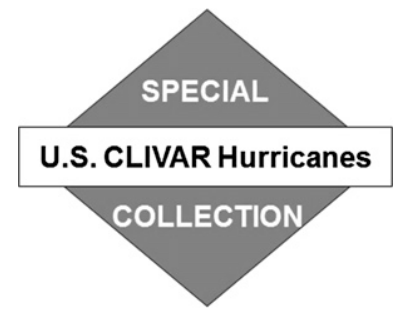

\title{
Sensitivity of Tropical Cyclones to Parameterized Convection in the NASA GEOS-5 Model
}

\author{
Young-Kwon Lim, ${ }^{*}$ Siegfried D. Schubert, ${ }^{+}$Oreste ReAle, ${ }^{\#}$ MyOng-In LeE, ${ }^{@}$ \\ ANDREA M. MOLOD, ${ }^{\&}$ AND MAX J. SUAREZ \\ * Global Modeling and Assimilation Office, NASA GSFC, Greenbelt, and Goddard Earth Sciences Technology \\ and Research, I. M. Systems Group, Rockville, Maryland \\ ${ }^{+}$Global Modeling and Assimilation Office, NASA GSFC, Greenbelt, Maryland \\ \# Global Modeling and Assimilation Office, NASA GSFC, and Goddard Earth Sciences Technology and Research, \\ Universities Space Research Association, Greenbelt, Maryland \\ ${ }^{\circledR}$ Ulsan Institute of Science and Technology, Ulsan, South Korea \\ \& Global Modeling and Assimilation Office, NASA GSFC, Greenbelt, and ESSIC, University of Maryland, \\ College Park, College Park, Maryland
}

(Manuscript received 3 February 2014, in final form 8 October 2014)

\begin{abstract}
The sensitivity of tropical cyclones (TCs) to changes in parameterized convection is investigated to improve the simulation of TCs in the North Atlantic. Specifically, the impact of reducing the influence of the Relaxed Arakawa-Schubert (RAS) scheme-based parameterized convection is explored using the Goddard Earth Observing System version 5 (GEOS-5) model at $0.25^{\circ}$ horizontal grid spacing. The years 2005 and 2006, characterized by very active and inactive hurricane seasons, respectively, are selected for simulation.

A reduction in parameterized deep convection results in an increase in TC activity (e.g., TC number and longer life cycle) to more realistic levels compared to the baseline control configuration. The vertical and horizontal structure of the strongest simulated hurricane shows the maximum wind speed greater than $60 \mathrm{~m} \mathrm{~s}^{-1}$ and the minimum sea level pressure reaching $\sim 940 \mathrm{mb}$, which are never achieved by the control configuration. The radius of the maximum wind of $\sim 50 \mathrm{~km}$, the location of the warm core exceeding $10^{\circ} \mathrm{C}$, and the horizontal compactness of the hurricane center are all quite realistic without any negatively affecting the atmospheric mean state.

This study reveals that an increase in the threshold of minimum entrainment suppresses parameterized deep convection by entraining more dry air into the typical plume. This leads to cooling and drying at the mid to upper troposphere, along with the positive latent heat flux and moistening in the lower troposphere. The resulting increase in conditional instability provides an environment that is more conducive to TC vortex development and upward moisture flux convergence by dynamically resolved moist convection, thereby increasing TC activity.
\end{abstract}

\section{Introduction}

This article is inspired by a recent research on tropical cyclone (TC) simulation coordinated by the U.S. Climate Variability and Predictability (CLIVAR) Hurricane Working Group (http://www. usclivar.org/working-groups/hurricane) Among various science issues raised in the research, it was found

Corresponding author address: Young-Kwon Lim, Bldg. 33, Code 610.1, 8800 Greenbelt Rd., Global Modeling and Assimilation Office, NASA GSFC, Greenbelt, MD 20771.

E-mail: young-kwon.lim@nasa.gov that many current general circulation models (GCMs) seriously underestimate TC activity over the North Atlantic when run at $\sim 0.5^{\circ}$ latitude/longitude or coarser horizontal grid spacing as opposed to some other basins such as the North Pacific (Walsh et al. 2013; Shaevitz et al. 2014). Only a few recent GCMs simulate TC activity in the North Atlantic with some success (e.g., Zhao et al. 2009). A question is raised as to whether horizontal grid spacing finer than $\sim 0.5^{\circ}$ is necessary to achieve reasonable TC numbers over the North Atlantic, even though resolution appears less critical for simulating TC numbers than the intensity (Strachan et al. 2013). Compared to TC numbers, 


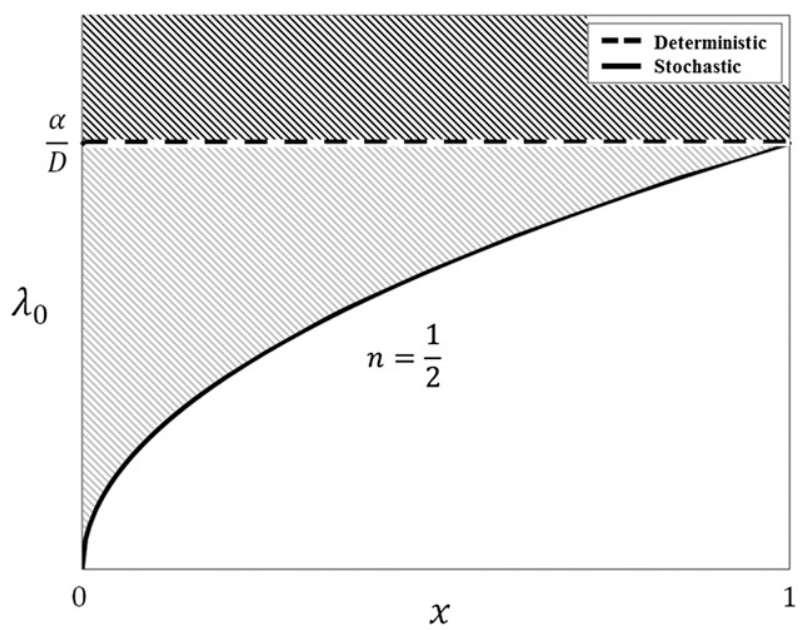

FIG. 1. Profile of $\lambda_{0}\left(\mathrm{~km}^{-1}\right)$ as a function of $x$ in Eq. (1) with $n=1 / 2$ (solid curve). A straight dashed line represents the deterministic $\lambda_{0}=$ $\alpha / D$, which applies the Tokioka constraint identically at every time step. The entrainment rate of convective plumes needs to be higher than $\lambda_{0}$, which range is represented with the black hatched area for the deterministic method. The entrainment rate allowed for the stochastic method is represented with both the black and gray hatched areas.

simulating realistic TC intensity and spatial structure appears more unattainable at these grid spacings ( $\sim 0.5^{\circ}$ or coarser), with generally weak and poorly organized systems occurring in all the GCMs (more than 10) involved in the working group. Higher resolution may be more appropriate to allow for a better representation of African easterly waves and the associated strong low-level vorticity, leading to more realistic simulation of Atlantic TC activity including number, intensity, life cycle, and spatial structure (Atlas et al. 2005; Knutson et al. 2007; Caron et al. 2011; Putman and Suarez 2011; Daloz et al. 2012; Emanuel 2013).

Several previous studies have identified deficiencies in the simulation of moist convective processes as substantially affecting the ability to simulate TC characteristics (Slingo et al. 1994; Zhang and McFarlane 1995; Smith 2000; Sanderson et al. 2008; Zhao et al. 2012). Smith (2000) suggests that major improvements in TC predictions will depend on improvements in the representation of convection in hurricane models. Knutson and Tuleya (2004), LaRow et al. (2008), Ma and Tan (2009), and Reed and Jablonowski (2011) performed model experiments to examine the sensitivity of the global TC numbers to changes in the convective parameterizations. Shen et al. (2006) and Stan (2012) examined the impact of disabling the convective parameterizations [in particular the schemes developed by Arakawa and Schubert (1974) and Moorthi and Suarez (1992)] on GCM hurricane forecasts. Both studies agreed on that explicit representation of cloud processes produces a larger number of TC events, with stronger intensity and longer life cycles (Reed and Jablonowski 2011; Stan 2012). However, the details of the atmospheric processes responsible for altering TC activity were not the focus of the above studies. Some of the atmospheric responses to changes in deep convective activity are discussed in Zhao et al. (2012), which focuses on the impacts on vertical velocity, temperature, and humidity. That study identifies stronger sensitivity of midtropospheric vertical motion to the minimum entrainment compared with the other variables (humidity and vertical wind shear); the importance of the response of vertical motion is also discussed in Oouchi et al. (2006).

The sensitivity of the atmospheric response to the convective parameterization and its impact on TC activity motivates the current study to improve the simulation of TC activity over the North Atlantic in GCMs. As in Tokioka et al. (1988), Held et al. (2007), and Kang et al. (2008), we find that increasing the threshold of minimum entrainment rate makes the convective plume entrain more dry air as it ascends, losing in-cloud buoyancy more rapidly when entraining. As a result, deep convection is inhibited from occurring in updrafts with a lateral entrainment rate $\lambda$ lower than a threshold value $\lambda_{0}$ (Tokioka et al. 1988; Held et al. 2007). Parameterized deep convection, including the subgrid-scale cloud representation, is restricted by increasing $\lambda_{0}$ (Held et al. 2007; Kang et al. 2008), while the fraction of large-scale condensation by nonconvective clouds increases through the large-scale cloud/condensation module (Tiedtke 1993) as opposed to the convection module (Kang et al. 2008). Wang (2014) found that this nondeep convection plays a role in moistening the lower to middle troposphere whereas deep convection moistens the upper troposphere. Zhao et al. (2012) also found that an inhibition of the convective parameterization through enhanced lateral mixing into convective plumes leads to increased TC genesis, along with a colder and drier upper troposphere.

The main objective of this study is to improve the simulation of North Atlantic TC activity in the $\mathrm{Na}$ tional Aeronautics and Space Administration (NASA) Goddard Earth Observing System version 5 (GEOS-5) model (Rienecker et al. 2008; Molod et al. 2012), including the TC number, intensity, life cycle, and horizontal/vertical structures. We focus on the cumulus entrainment rate in the GEOS-5 model run at a relatively fine grid spacing $\left(0.25^{\circ}\right)$ to determine the thresholds of minimum entrainment that reliably reproduce the TC activity over the North Atlantic. An important aspect of this study is that we also focus on maintaining a realistic mean climate state-an aspect 
TABLE 1. The number of TCs (from third to fifth column) detected for the period of June-November each year over four different regions listed on the first column. Rightmost column represents the observed TC numbers archived at the International Best Track Archive for Climate Stewardship (IBTrACS) (Knapp et al. 2010). The values in parentheses are the number of strong TCs up to the level of hurricane or typhoon.

\begin{tabular}{|c|c|c|c|c|c|}
\hline & & ExpA & ExpB & ExpC (control run) & Observation \\
\hline \multirow[t]{2}{*}{ Atlantic } & 2005 & $36(24)$ & $25(15)$ & $18(8)$ & $29(15)$ \\
\hline & 2006 & $27(21)$ & $13(8)$ & $8(6)$ & $10(5)$ \\
\hline \multirow[t]{2}{*}{ Western Pacific } & 2005 & $28(14)$ & $24(15)$ & $12(10)$ & $20(11)$ \\
\hline & 2006 & $32(17)$ & $25(17)$ & $14(11)$ & $22(7)$ \\
\hline \multirow[t]{2}{*}{ Eastern Pacific } & 2005 & $28(9)$ & $9(4)$ & $5(3)$ & $15(6)$ \\
\hline & 2006 & $29(12)$ & $18(7)$ & $8(3)$ & $20(10)$ \\
\hline \multirow[t]{2}{*}{ Indian Ocean } & 2005 & $3(0)$ & $4(2)$ & $3(1)$ & $3(0)$ \\
\hline & 2006 & $5(0)$ & $3(0)$ & $2(0)$ & $4(0)$ \\
\hline
\end{tabular}

of the simulations (the response of the mean state to the changes in deep convection) that many previous studies have not emphasized. The analysis of the runs is geared to better understanding the atmospheric response determining the TC activity over the North Atlantic with a particular focus on the atmospheric instability over the TC genesis region, the thermodynamic and radiative balance, the low-level fluxes and circulation, and the mean climate state response.

The organization of the paper is as follows. Section 2 describes the GEOS-5 model and the experimental design. The results of the sensitivity experiments are presented in section 3, including TC numbers, intensity, life cycle, and spatial structure of the strongest hurricanes. We investigate in section 4 the relevant atmospheric dynamics and physics to explain the TC activity changes that occur as a result of the modifications to the parameterized deep convection. Some verification of the atmospheric basic state changes due to the deep convection changes is also provided in section 4 , followed by concluding remarks and discussion in section 5 .

\section{Model and experimental design}

\section{a. Model}

We utilize the NASA GEOS-5 model (Rienecker et al. 2008; Molod et al. 2012) for our experiments. The model is run with 72 hybrid-sigma vertical layers, extending to $0.01 \mathrm{hPa}$, and $\sim 0.25^{\circ}$ latitude/longitude horizontal grid spacing. The convection scheme in the GEOS-5 model is a modified version of the relaxed Arakawa-Schubert (RAS) scheme of Moorthi and Suarez (1992). In this version, multiple convective plumes in RAS have the convection base level at the top of the planetary boundary layer. The adjustment time scale of plumes is a function of the vertical depth of the plumes, which varies from $0.5 \mathrm{~h}$ for the shallowest plume to $12 \mathrm{~h}$ for the deepest. Another major modification to RAS, which affects convective variability of the model substantially and hence the intensity of simulated TCs, is the stochastic determination of the minimum entrainment threshold. This is basically the same as in Tokioka et al. (1988), limiting the frequent adjustment of deep convection and increasing the variability of deep convection (Lee et al. 2003; Lin et al. 2008). For the Tokioka constraint in this study, the threshold value is determined randomly with a predetermined power function:

$$
\lambda_{0}=\frac{\alpha}{D} x^{n}, \quad 0 \leq x \leq 1,
$$

where $\alpha$ is a free parameter, $D$ is the depth of the subcloud layer, and $x$ is a random number chosen at every model integration time step. Here the depth of the subcloud layer, $D$, is assumed to be related to the plume radius (Simpson and Wiggert 1969). The stochastic determination allows one to consider the spatial statistics of the observed cloud widths (or radius) and volumes

TABLE 2. List of the threshold values for detecting the TC using the detection/tracking algorithm based on Vitart et al. (2003).

\begin{tabular}{|c|c|c|c|c|c|}
\hline Variables & $\begin{array}{l}\text { Local relative } \\
\text { vorticity maximum } \\
\quad(850 \mathrm{hPa})\end{array}$ & Warm core & $\begin{array}{l}\text { Minimum sea level } \\
\text { pressure (SLP) }\end{array}$ & $\begin{array}{l}\text { Minimum } \\
\text { lower-level } \\
\text { wind speed }\end{array}$ & $\begin{array}{c}\text { Minimum } \\
\text { duration }\end{array}$ \\
\hline Criteria & $1.0 \times 10^{-4} \mathrm{~s}^{-1}$ & $\begin{array}{l}\text { Distance between the TC center } \\
\text { and the center of the warm core } \\
\text { must not exceed } 2^{\circ} \text { lon/lat }\end{array}$ & $\begin{array}{l}\text { Minimum SLP defines the TC } \\
\text { center and must exist within } \\
2^{\circ} \times 2^{\circ} \text { radius of the vorticity } \\
\text { maximum }\end{array}$ & $17 \mathrm{~m} \mathrm{~s}^{-1}$ & 4 days \\
\hline
\end{tabular}


Atlantic TSC tracks (2005)
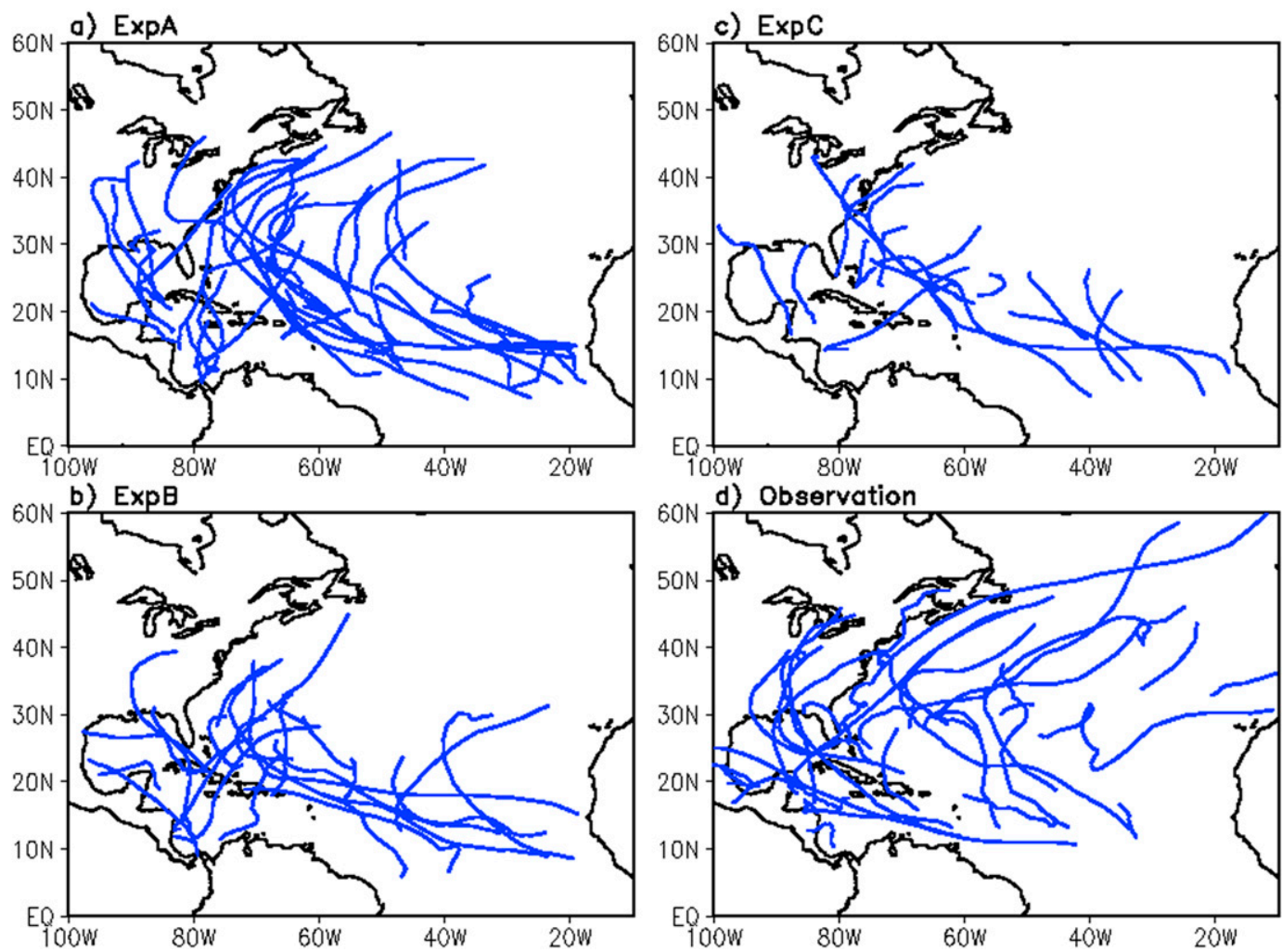

FIG. 2. TC tracks for 2005 for (a) ExpA, (b) ExpB, (c) ExpC, and (d) observations.

that have been found to follow a power-law distribution by Bacmeister and Stephens (2011) using CloudSat data (Stephens et al. 2002). Figure 1 compares the minimum entrainment threshold values between the conventional, deterministic method of Tokioka et al. (1988) and the stochastic method in this study. Entrainment rate of convective plume needs to be greater than $\lambda_{0}$ (minimum entrainment threshold value) to allow deep convection, which is represented by hatched area in Fig. 1. In case of $n=1 / 2$, which is used in this study to consider power-law behavior in the observed cloud width distribution, the threshold curve increases with the square root function (Fig. 1), and reverts to the conventional Tokioka constraint. This tends to impose restrictions on the entrainment rate in most cases, but occasionally allows a very deep and less entraining convection plume. Putman and Suarez (2011) used the same version of GEOS-5 that was used in this study for their tropical cyclone simulation, but with much finer grid spacing of $\sim 7 \mathrm{~km}$.

Increasing the Tokioka constraint (i.e., an increase in the threshold of minimum entrainment) restricts the development of subgrid-scale deep convection, while at the same time favoring resolved-scale nonconvective clouds, leading to more active large-scale cloud/ condensation and precipitation processes.

\section{b. Experimental design}

Three types of experiments were carried out by applying different Tokioka constraints in the model simulations for 2005 and 2006, which are very active and inactive hurricane years, respectively. Experiment A (ExpA) has the strongest Tokioka constraint, so that it has the greatest possibility of large thresholds of minimum entrainment, while experiment $\mathrm{B}$ corresponds to an intermediate range of thresholds $(\mathrm{ExpB})$ and experiment $\mathrm{C}(\mathrm{ExpC})$, which is a baseline control run, corresponds to the lowest minimum entrainment range that allows more parameterized deep convection relative to ExpA and ExpB. These were implemented in the model with the minimum values $\alpha / D=2 \mathrm{~km}^{-1}(\operatorname{ExpA}), 0.7 \mathrm{~km}^{-1}(\operatorname{ExpB})$, and $0.45 \mathrm{~km}^{-1}$ $($ ExpC) in Eq. (1). Each type of experiment consists of three ensemble members. All simulations are done with prescribed weekly sea surface temperature (SST) forcing [theHadley Centre Sea Ice and Sea Surface Temperature dataset (HadISST) values from Rayner et al. (2003)], and are initialized from the Modern-Era 
Atlantic TSC tracks (2006)
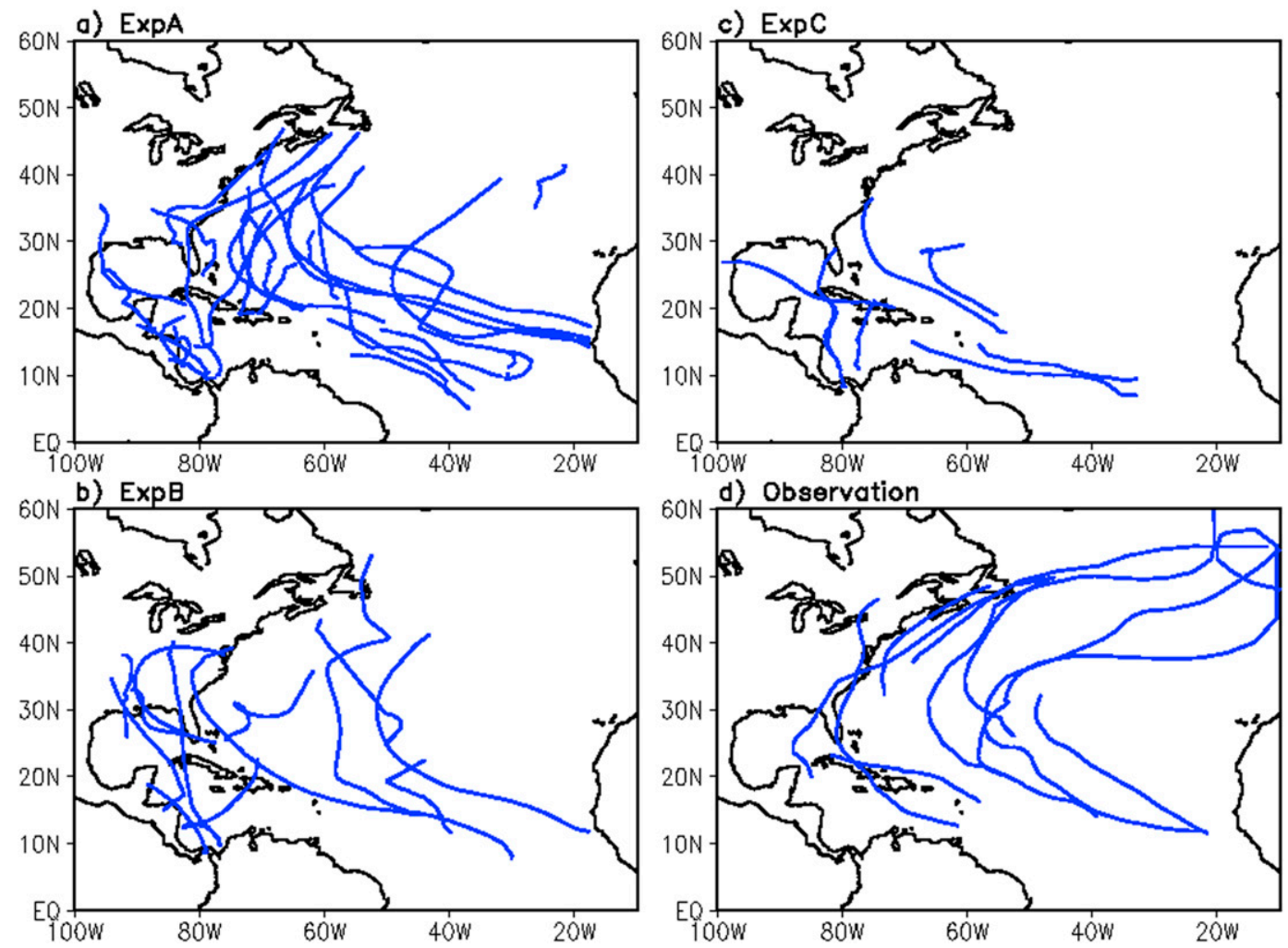

FIG. 3. As in Fig. 2, but for 2006.

Retrospective Analysis for Research and Applications (MERRA; Rienecker et al. 2011) data on 1, 8, and 15 May of each year.

\section{Sensitivity of TC characteristics to changes in parameterized deep convection}

TCs are detected for June through November of each year (2005 and 2006) and for each experiment (ExpA, ExpB, and ExpC). The number of detected tropical storms and hurricanes for the North Atlantic domain is shown in the second and third row of Table 1 . The basic algorithm of TC detection and tracking is the same as that used in Vitart et al. (2003), Knutson et al. (2007), and LaRow et al. (2008). Threshold values for wind speed, relative vorticity, warm core, sea level pressure (SLP), and minimum duration time are assigned in the algorithm to define TC (Table 2) at a quarter-degree grid spacing based on suggestions in Walsh et al. (2007). The threshold values used here can be considered realistic because they are very close to the thresholds to detect TCs from observational data. ExpA produces an excessive number of tropical storms and hurricanes, compared with observations shown on the rightmost column (Table 1). In particular, it produces too strong TC activity (more than 20 hurricanes) even in 2006, which was recorded as a relatively calm hurricane year over the North Atlantic (see the third row in Table 1) (Knapp et al. 2010). ExpB produces more reasonable TC numbers, as they are closer to observations than either ExpA or ExpC. ExpC shows generally weak TC activity and produces much weaker than observed TC activity during the active hurricane season of 2005. This basic result of the model producing an excessive number of TCs in ExpA and a more reasonable number of TCs in ExpB is also true for the other basins including the western Pacific and eastern Pacific (the fourth through seventh rows in Table 1). One limitation found in ExpB is that the number of hurricanes is significantly overestimated for the western Pacific in 2006. It suggests that the western Pacific region would need smaller reduction of parameterized deep convection than that applied to ExpB for more realistic TC simulation. Walsh et al. (2013) also addressed that most global models tend to produce more realistic TC activity over the western Pacific than the Atlantic.

The number of TCs simulated over Indian Ocean ranges between 2 and 5 for the three experiments with 
SLP \& Wind scatter diagram (2005)

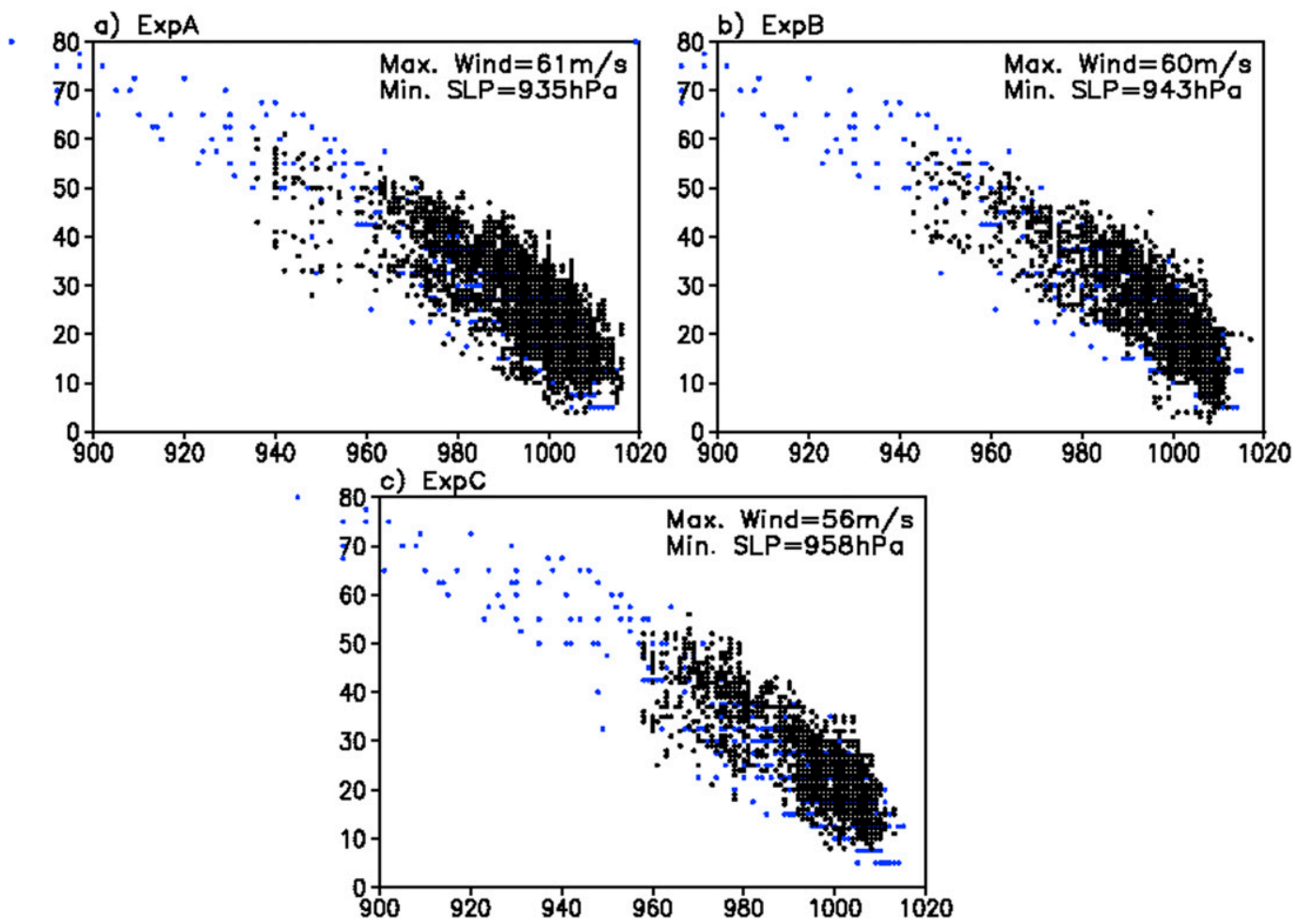

FIG. 4. Scatter distribution of sea level pressure (SLP; hPa) and lower-level wind speed $\left(\mathrm{m} \mathrm{s}^{-1}\right)$ of TCs in 2005 for (a) ExpA, (b) ExpB, and (c) ExpC. Wind speed in blue dots represents observed maximum sustained wind (Knapp et al. 2010) while wind speed in black dots represents model-produced wind at lower levels from the surface to $850 \mathrm{hPa}$.

slightly more TCs in ExpA and ExpB, compared to ExpC (the bottom two rows in Table 1). The results, summarized in Table 1, demonstrate that a reduction of parameterized deep convection tends to increase TC frequency not only in the Atlantic, but also in the other ocean basins. Such a global increase in the TC numbers was also discussed in Zhao et al. (2012), while Murakami et al. (2012) produced increases in TCs in all but the eastern Pacific region through a reduction in parameterized deep convection.

TC tracks are plotted for each experiment. During the 2005 season (Fig. 2), a variety of tracks were observed: 1) Cape Verde-type TC systems that crossed the Atlantic making landfall over the American continent, 2) early recurvers, 3) Gulf of Mexico TCs, and also 4) eastward tracking systems embedded in the westerlies. Comparison between the experiments indicates that ExpA and ExpB both display a variety of tracks much larger than ExpC, and closer to the observation. The results for 2006 (Fig. 3) show features similar to those obtained for 2005 in the sense that the increased thresholds of minimum entrainment produce larger number of TCs with longer life cycles and a track variety more similar to the observation over the Atlantic. This model response is consistent with Emanuel et al. (2008) and Stan (2012), who showed a sensitivity of TC activity to changes in the cumulus parameterization in the Community Climate System Model (CCSM; Gent et al. 2011). We additionally calculate the accumulated cyclone energy (ACE) to account for the number, intensity, and duration of all TCs plotted in Figs. 2 and 3. For 2005, the approximate ACEs $\left(10^{4} \mathrm{kt}^{2}\right)$ for three experiments are, respectively, 340, 210, and 120, while ACEs for 2006 are 215, 100, and 55, respectively [observation: $\sim 270(2005)$ and $\sim 80$ (2006); http://www.cpc.ncep.noaa.gov/products/outlooks/ background_information.shtml]. ACE values confirm an excessive TC activity in ExpA for both years (cf. observed ACEs). In contrast, ExpC represents much weaker TC activity than observation in 2005. ExpB demonstrates a better job than the other two experiments as the ACEs for ExpB are closest to the observed ACEs.

Additional details of the model responses (including TC activity, TC intensity, and vertical hurricane structure) produced in each experiment are shown in Figs. 4-8. Scatterplots of low-level (surface to $850 \mathrm{hPa}$ ) wind versus SLP for 2005 (Fig. 4) show that the maximum wind speed 
SLP \& Wind scatter diagram (2006)

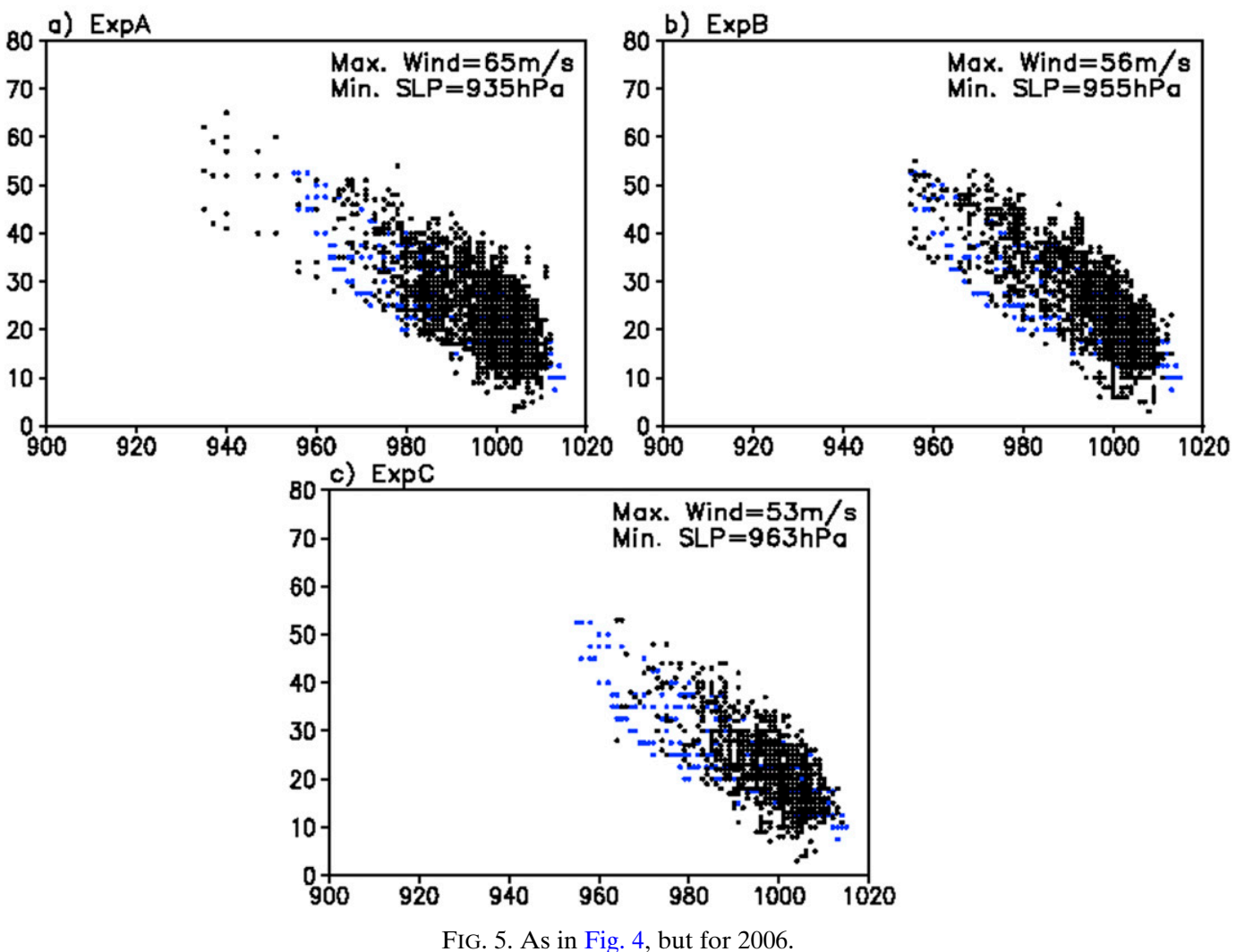

is up to $61 \mathrm{~m} \mathrm{~s}^{-1}$ in $\operatorname{ExpA}, 60 \mathrm{~m} \mathrm{~s}^{-1}$ in $\operatorname{ExpB}$, and less than $60 \mathrm{~m} \mathrm{~s}^{-1}$ in ExpC. The minimum SLP is down to 935, 943, and $958 \mathrm{hPa}$ respectively in the three experiments. ExpA and ExpB reveal improved distributions of SLP and wind speed compared with ExpC. However, the observed wind speed is up to $80 \mathrm{~m} \mathrm{~s}^{-1}$ and minimum SLP deeper than $920 \mathrm{hPa}$ for extremely strong hurricanes-something not reproduced by the model in any of the experiments. It is likely that the simulation of category 5 hurricanes requires horizontal resolutions higher than the quarterdegree grid spacing used here (Shen et al. 2006; Reed and Jablonowski 2011; Bacmeister et al. 2014). Murakami et al. (2012) produced category 5 TCs using the Meteorological Research Institute Atmosphere General Circulation Model, version 3.2 (MRI-AGCM3.2) at a smaller grid spacing of $0.1875^{\circ}$. Still finer horizontal grid spacing (finer than $10 \mathrm{~km}$ ) such as that of the models considered in Noda et al. (2012) and Putman and Suarez (2011) has been shown to be beneficial for explicitly simulating convection and capturing such extremely strong hurricanes. Mallard et al. (2013) explored the resolution dependence of TC simulations by comparing runs with $6-\mathrm{km}$ and $18-\mathrm{km}$ grid spacing, using the Weather Research and Forecasting Model (WRF). That study found that TC frequency and the detailed spatial structure of strong TC such as smallerscale maxima embedded in the eyewall, greater spiral band activity, and storm asymmetry were remarkably improved with the $6-\mathrm{km}$ grid spacing. It is noteworthy that the maximum wind speeds identified in ExpA and ExpB in the present study are comparable to those found in the idealized hurricane experiment of Reed and Jablonowski (2011). They simulated maximum wind speeds of $\sim 60 \mathrm{~m} \mathrm{~s}^{-1}$ at a quarter-degree horizontal grid spacing.

Figure 5 is the same as Fig. 4 but for 2006. The results show that the simulated wind speeds and minimum center SLP deepening for very strong hurricanes is comparable to or stronger than those for the observations (ExpA and ExpB). In contrast, ExpC exhibits weaker maximum wind and minimum SLP distribution compared with the observations.

The vertical structure of the strongest hurricane for ExpA is plotted in Fig. 6. The top left panel shows the wind speed (shaded) and temperature (contoured), and the right panel shows the warm core. Note that Fig. 6a displays a latitude-height cross section as this hurricane is moving westward over Gulf of Mexico as it reaches its maximum intensity, with the peak wind speed occurring 

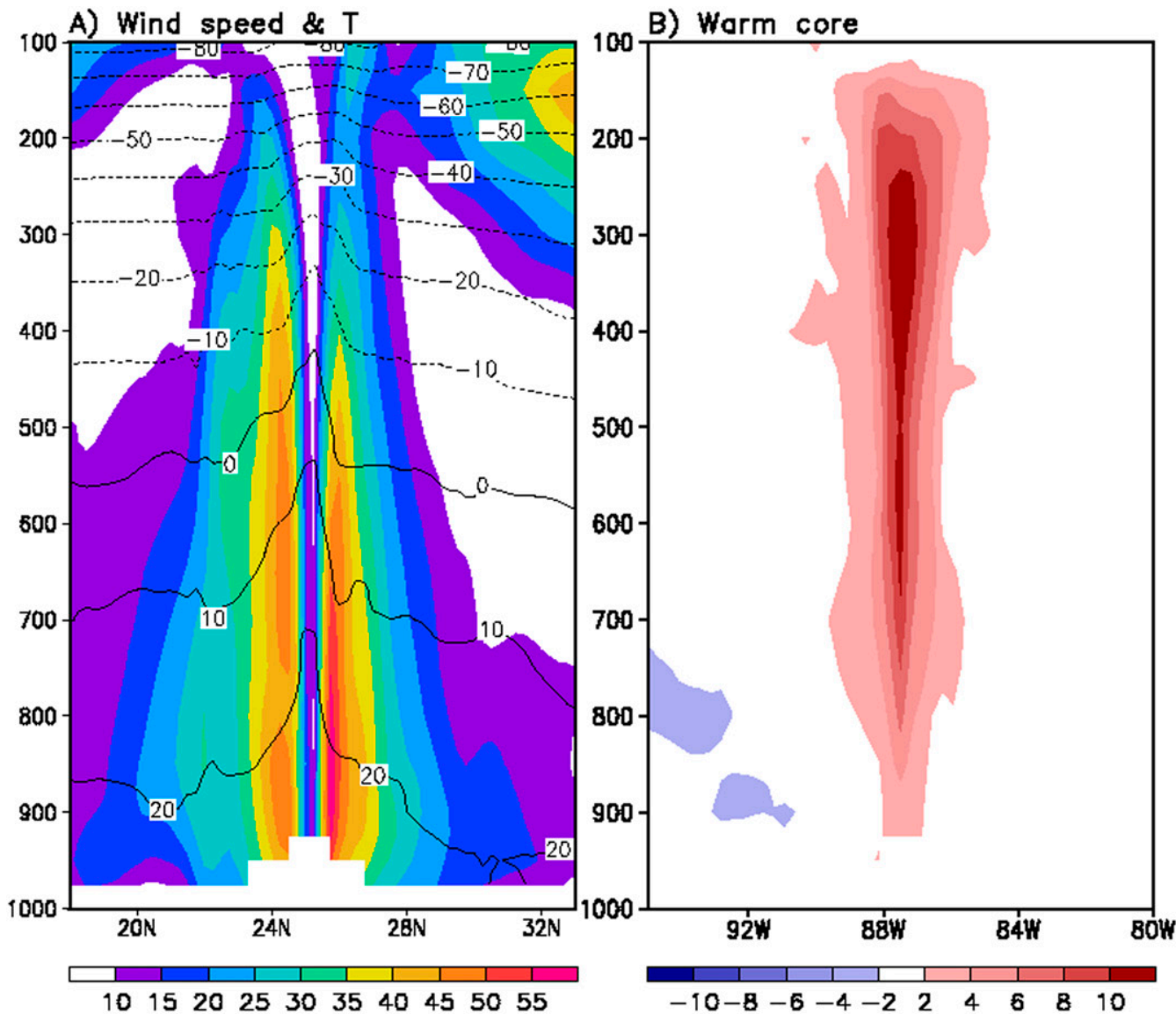

C) Evolution of SLP (blue) \& max. wind (black) at hurricane center

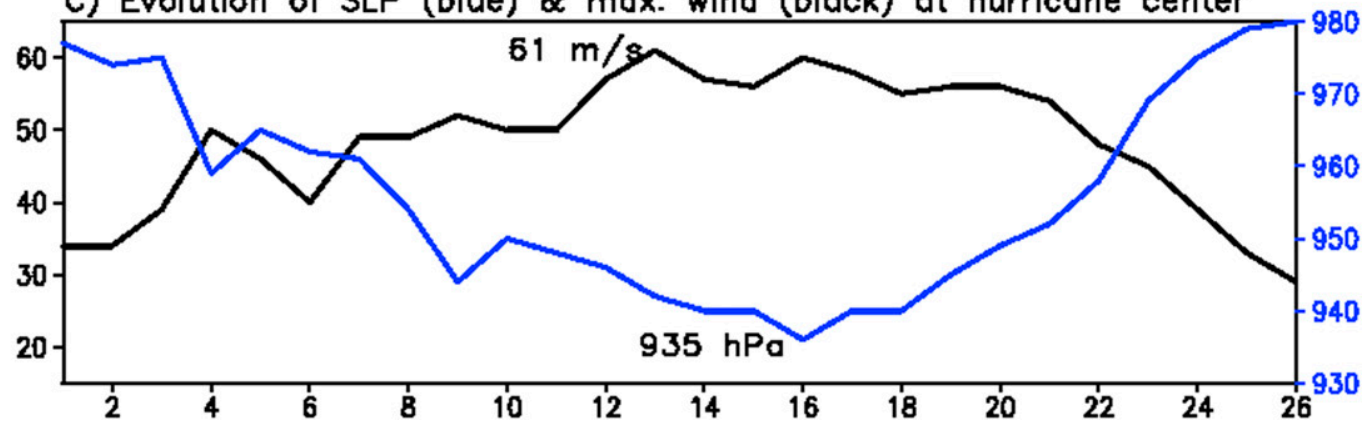

FIG. 6. (top) Vertical cross section of the strongest hurricane in 2005 simulated by ExpA. (a) Shaded and contoured are the latitude-height cross sections of wind speed $\left(\mathrm{m} \mathrm{s}^{-1}\right)$ and temperature (K), respectively. (b) The longitudeheight cross section of warm core $(\mathrm{K})$ computed as temperature deviation from zonal mean over $40^{\circ}$ longitudes with a hurricane core centered. (c) The black line denotes the time evolution of the maximum wind speed at hurricane center whereas the blue line indicates the minimum SLP. (d)-(f) As in (a)-(c), but for 2006.

on the right side of westward moving hurricane rather than on the left side. In contrast, Figs. 7a and 8a display longitude-height cross sections as the hurricanes move northward. The results for 2005 show a compact core and hurricane eye that is well defined. The maximum wind speeds (greater than $60 \mathrm{~m} \mathrm{~s}^{-1}$ ) and the radius of maximum winds (less than $50 \mathrm{~km}$ ) both correspond to very realistic
TC representation. The warm core value is greater than $10^{\circ} \mathrm{C}$ and situated in the upper troposphere, quite similar to the typical structure of observed hurricanes (Frank 1977). The bottom panel is the time series of the minimum SLP and maximum wind speed following the moving hurricane. The minimum SLP drops to $935 \mathrm{hPa}$ and maximum wind speed reaches $61 \mathrm{~m} \mathrm{~s}^{-1}$. The main features 

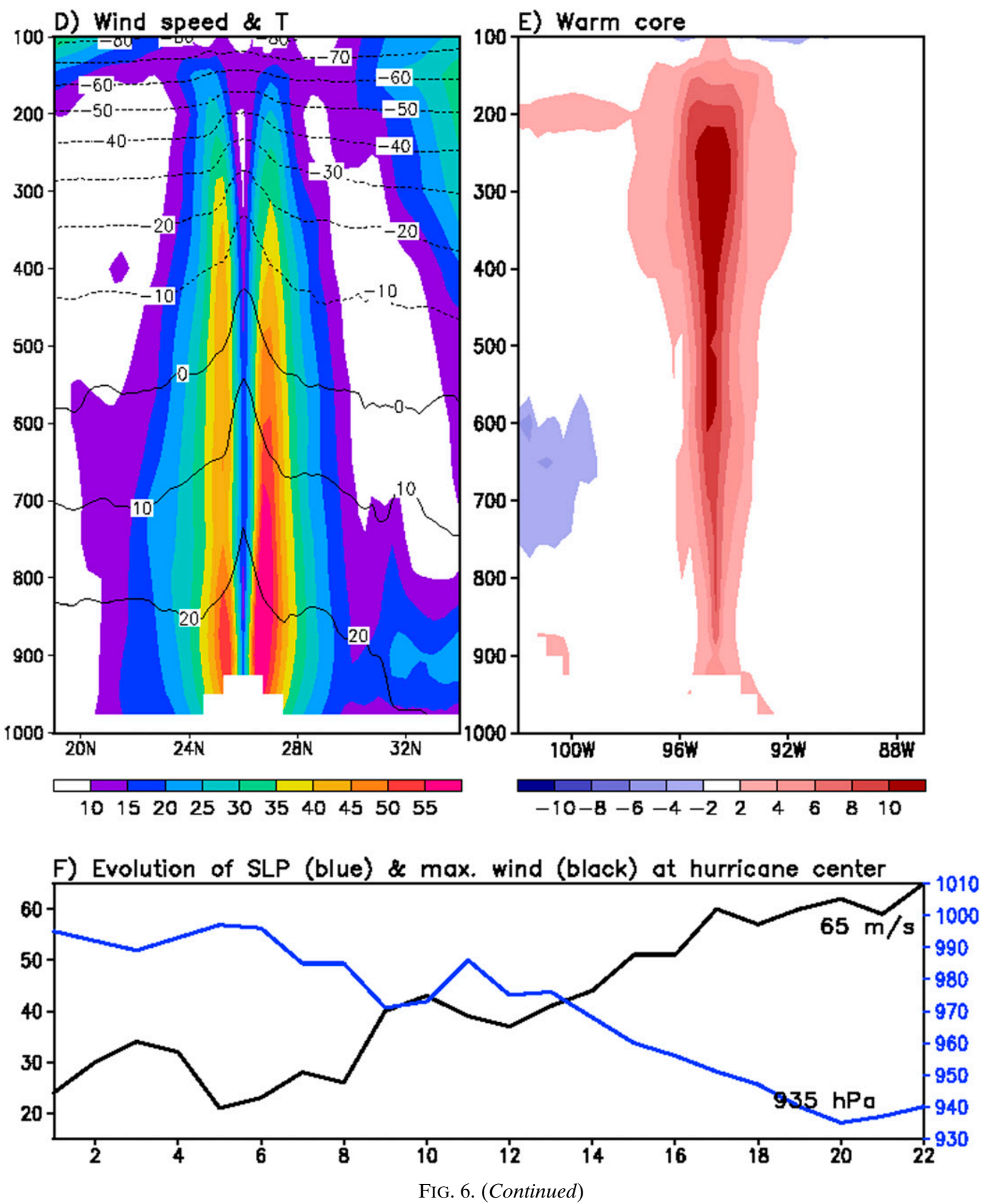

for 2006 are quite similar to those found for 2005, showing a well-defined hurricane characterized by a maximum wind speed of $65 \mathrm{~m} \mathrm{~s}^{-1}$ and minimum SLP of $935 \mathrm{hPa}$.

The vertical structures of the strongest hurricanes in ExpB are shown in Fig. 7. Compared with ExpA, they are a little weaker, but still show a reasonable vertical structure in terms of compactness of the core, with the radius of the maximum wind less than $\sim 50 \mathrm{~km}$ (two grid points in longitudinal direction), the maximum wind value near $60 \mathrm{~m} \mathrm{~s}^{-1}$, the minimum SLP of about $940 \mathrm{hPa}$, and vertical profile of the warm core reaching $10^{\circ} \mathrm{C}$ at upper-troposphere in 2005. However, as already discussed in connection with Fig. 4, quarter-degree horizontal grid spacing appears to be too coarse to produce an extremely strong hurricane showing wind speed greater than $\sim 70 \mathrm{~m} \mathrm{~s}^{-1}$ and SLP lower than $\sim 930 \mathrm{hPa}$. In 2006, the model produces a major hurricane with $56 \mathrm{~m} \mathrm{~s}^{-1}$ (wind speed) and $955 \mathrm{hPa}$ (SLP), which is the strongest hurricane found also in the observations that year (blue dots in Figs. 5 and 7d-f).

ExpC, which is the control run, also shows reasonable results (Fig. 8), although the storms are less organized 

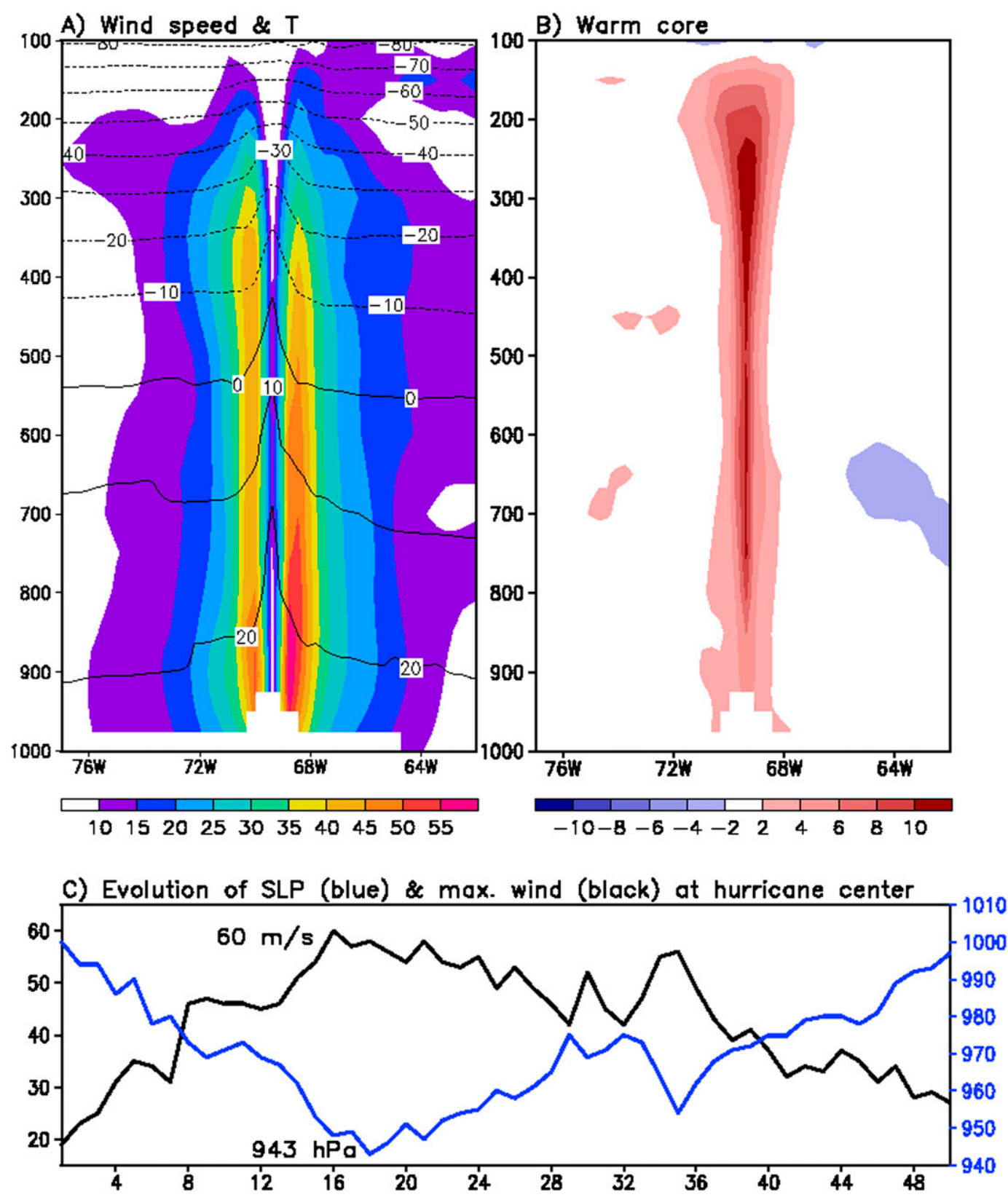

FIG. 7. As in Fig. 6, but for ExpB. Note that (a),(b),(d), and (e) are longitude-height cross sections.

than those found in the other two experiments. The warm core is weak with a value of approximately $6^{\circ}-8^{\circ} \mathrm{C}$ and located in the midtroposphere. The wind speed, SLP, and compact structure of the hurricane core are also not as realistic as those in ExpA and ExpB. The weak hurricane structures found in ExpC are not inconsistent with the study of Vitart et al. (2001), which found that the vertical structures of hurricanes simulated by RAS tend to be less intense and have lower warm cores than those produced with moist convective adjustment (MCA) schemes (Manabe 1969), although the RAS scheme produces more TCs and higher relative humidity than MCA schemes. In any event, the hurricane vertical structures shown in Figs. 6-8 provide compelling evidence that the suppression of parameterized deep convection tends to produce more intense hurricanes with better organized vertical structures.

\section{Atmospheric response to parameterized deep convection}

The physical mechanisms by which the suppression of the cumulus parameterization promotes TC activity are 

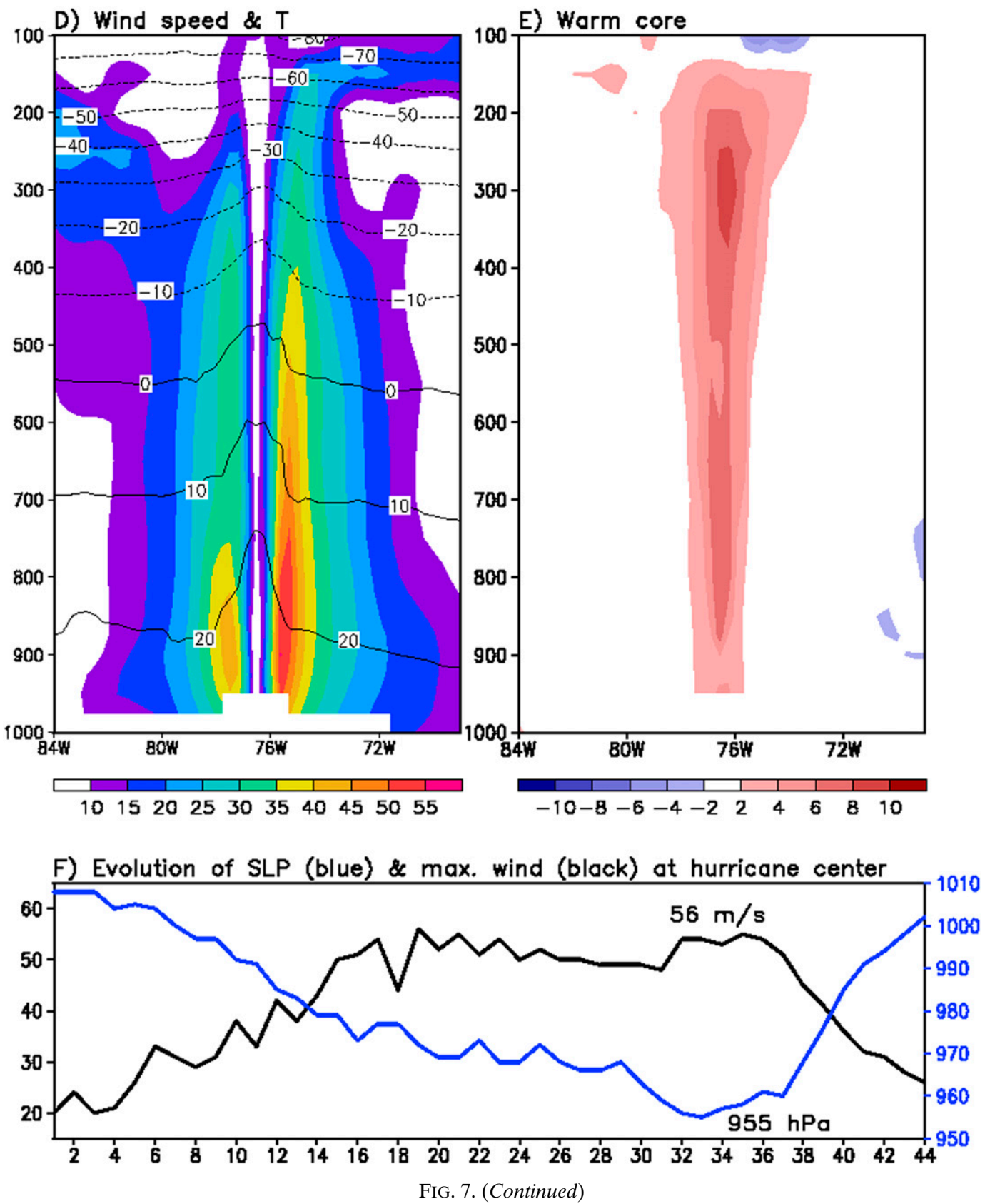

investigated next. For this analysis we first remove the regions occupied by the TCs from the model data in attempt to better focus on the environmental changes resulting from suppression of the parameterized deep convection. We recognize, however, that the resulting time-averaged patterns in Figs. 9-14 in which TCs were removed contain both 1) the environmental structure that promotes TC activity through suppressed deep convection and 2) the result of TC activity, which is known to stabilize the atmosphere and cannot be easily removed. Nevertheless, the results shown in Figs. 9-14 should provide useful information on the role of environment, by comparing the patterns between the three experiments. The role of atmospheric moist static stability - a factor known to affect TC characteristics (Smith 2000)-is shown in Fig. 9, where the vertical profile of moist static energy (left panel) and the vertical gradient of equivalent potential temperature (right panel) are computed over the TC genesis region, which covers most of the central and eastern tropical Atlantic $\left(5^{\circ}-20^{\circ} \mathrm{N}, 60^{\circ}-15^{\circ} \mathrm{W}\right)$. Profiles from ExpA, ExpB, and ExpC all exhibit a decrease with height in 

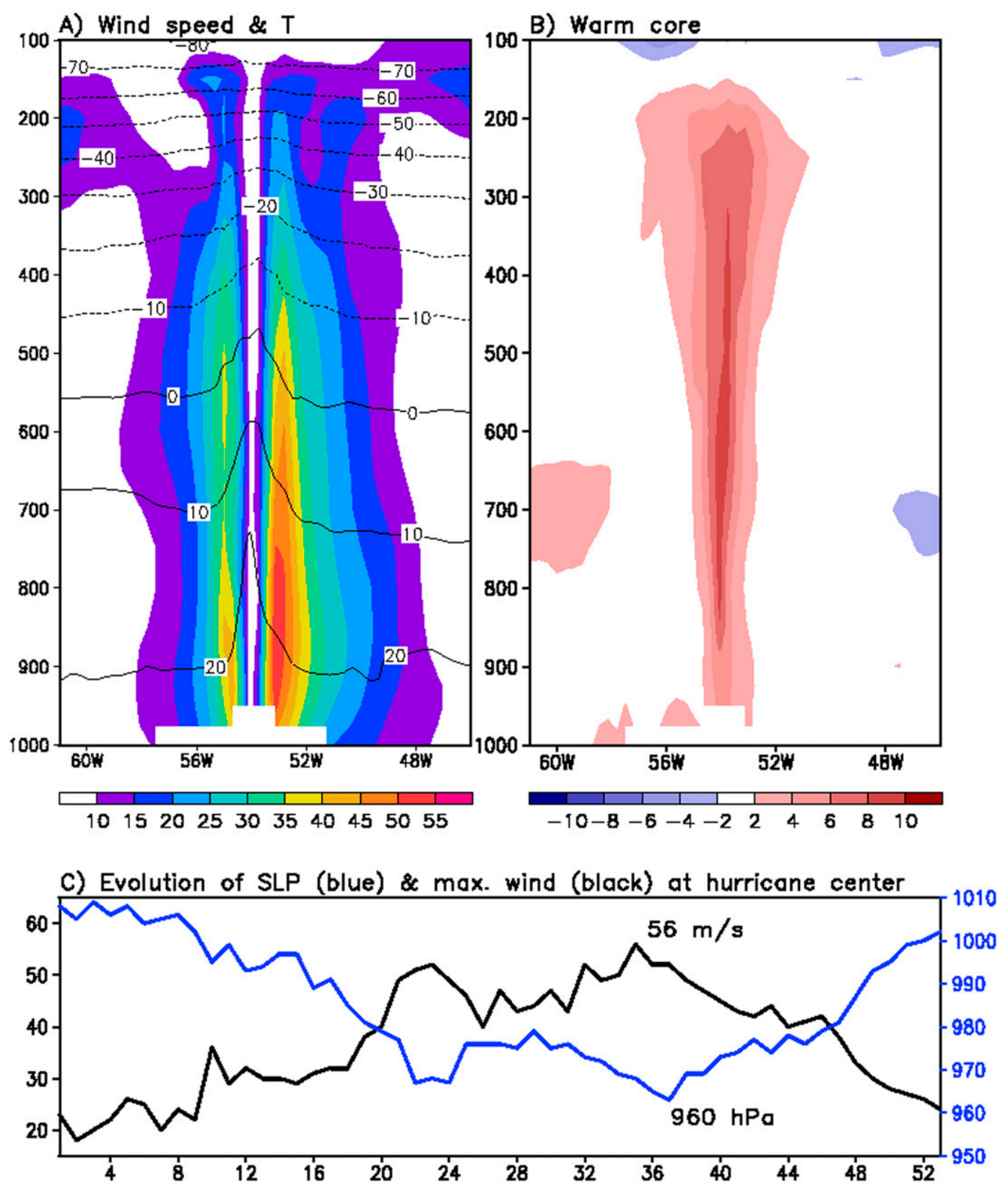

FIG. 8. As in Fig. 7, but for ExpC.

moist static energy at low levels (below 700-800-hPa height) and an increase at upper levels, implying the possibility of conditional instability. The ExpA result shows the possibility of stronger instability than ExpB and ExpC. The vertical gradient of equivalent potential temperature $\left(-\partial \theta_{e} / \partial P\right)$ (Fig. 9b) also shows that lower tropospheric vertical column with the negative $-\left(\partial \theta_{e} / \partial P\right)$ is more extensive in ExpA than the other two experiments, indicating that the most unstable atmosphere occurs in ExpA, followed by ExpB and ExpC.
The vertical temperature and humidity profiles are plotted over the TC genesis region in Fig. 10 to indicate how they are linked to the atmospheric instability. Here we plot the differences in the vertical profiles of temperature/humidity between two experiments. The most striking feature of these results is the mid- to uppertropospheric cooling (Fig. 10a) and drying (Fig. 10b) and lower-tropospheric moistening (Fig. 10b) resulting from the reduction in parameterized deep convection. This vertical structure of the humidity is in good agreement with the results of Zhao et al. (2012). With a larger 
D) Wind speed \& $T$

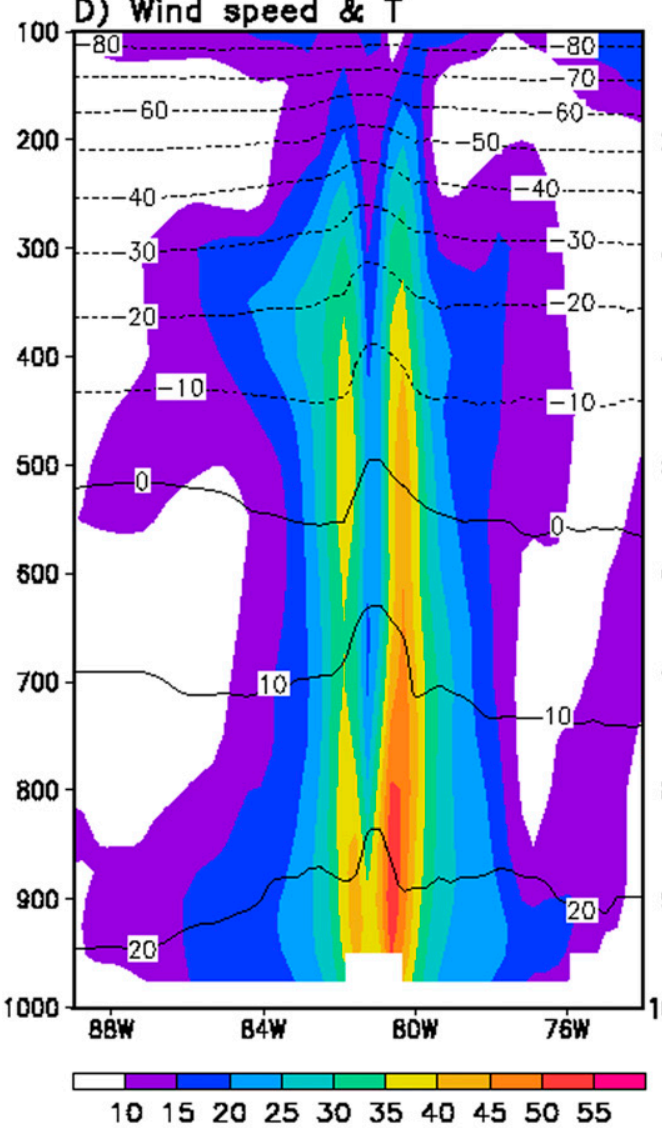

E) Warm core

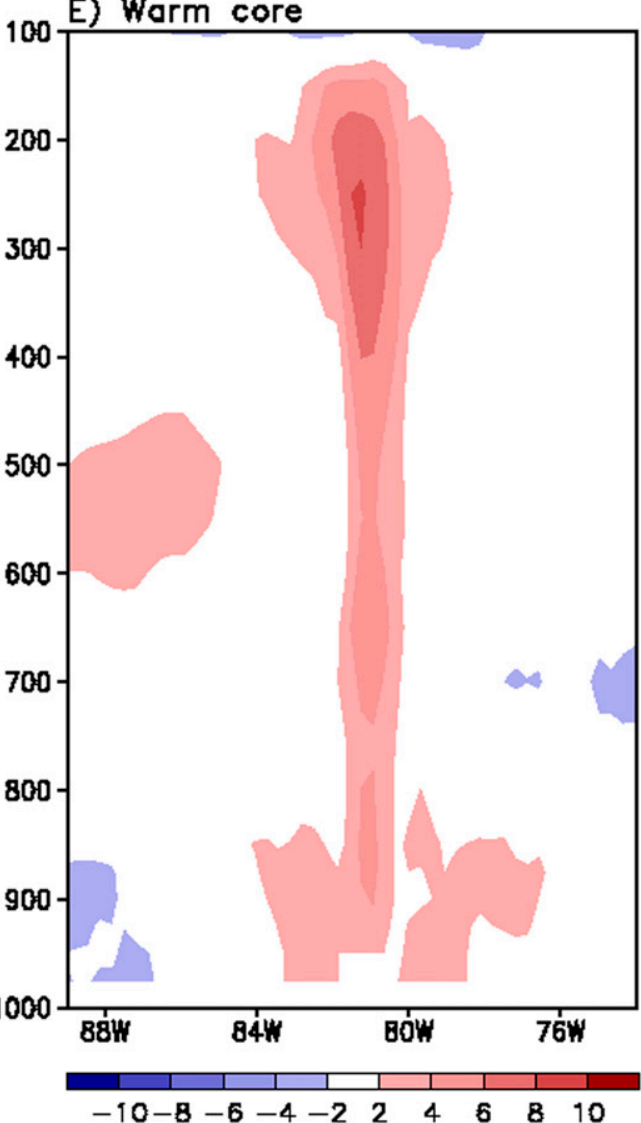

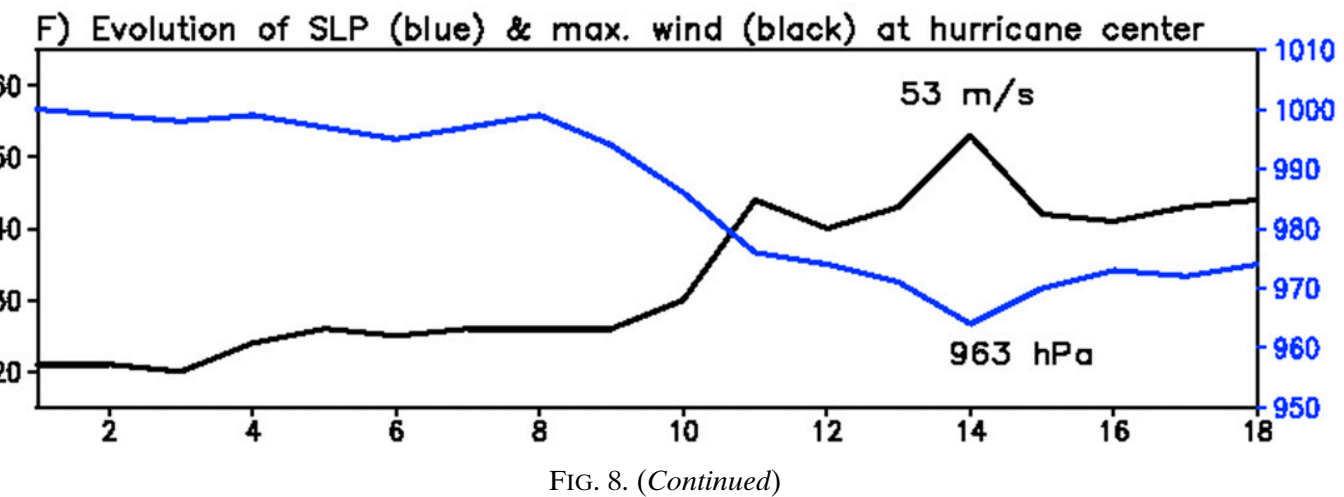

threshold of minimum entrainment, it is not unexpected that more dry air will be entrained into the plume, resulting in a drier upper atmosphere with decreased buoyancy (Held et al. 2007). The reduction of in-cloud buoyancy leads to the suppression of parameterized deep convection and less upper-tropospheric condensation heating. Figure 10 reflects such a change in the vertical profile of temperature and moisture, associated with an unstable atmosphere. Upward moisture flux and dynamically resolved convection are more likely to occur after the lower troposphere is moistened enough
(Wang 2014) under this unstable atmospheric condition. Shen et al. (2000) also addressed the role of instability in the environmental conditions associated with increasing TC activity by showing that TC intensity is well correlated with the maximum surface evaporation (moistening) and the environmental convective available potential energy (CAPE) (Fig. 11c).

Figure 11 shows the latent heating and evaporative flux with a focus on the near-surface moisture flux. We note that the differences between ExpB and ExpC exhibit very similar patterns although with smaller magnitude 
a) Moist Static Energy $(\mathrm{J} / \mathrm{kg})$

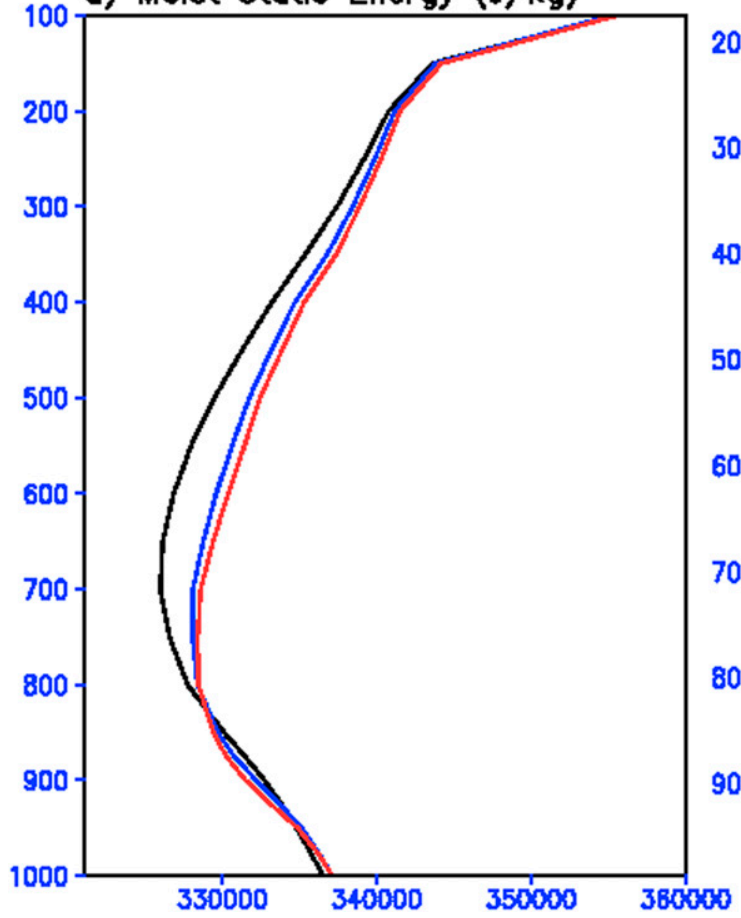

b) - partial(EPT)/partial(P)

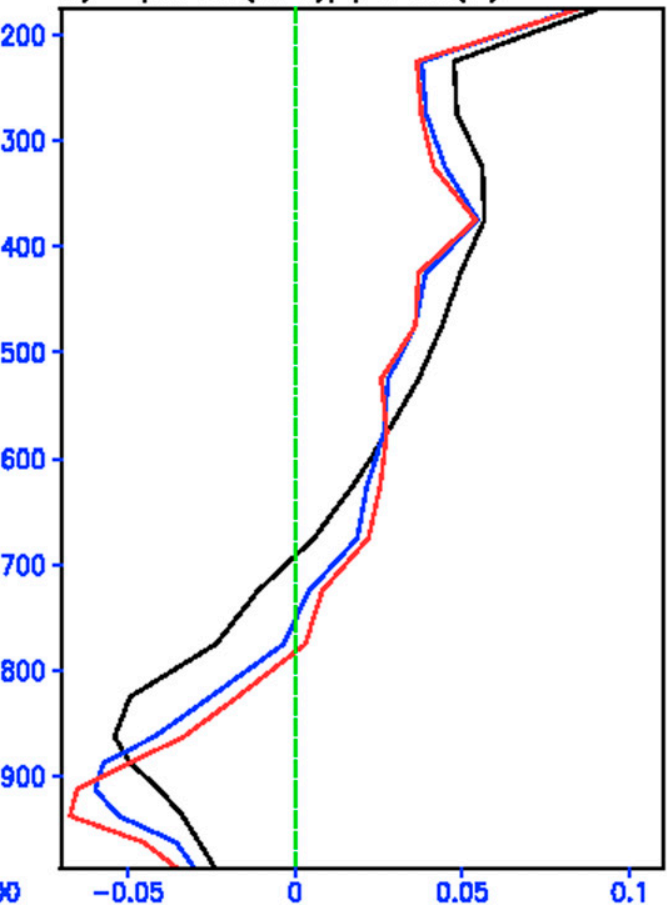

FIG. 9. Vertical profile of area-averaged (a) moist static energy $\left(\mathrm{J} \mathrm{kg}^{-1}\right)$ and (b) vertical gradient of equivalent potential temperature $\left(-\partial \theta_{e} / \partial P\right)\left(\mathrm{K} \mathrm{hPa}^{-1}\right)$ from $\operatorname{ExpA}$ (black), $\operatorname{ExpB}$ (blue), and $\operatorname{ExpC}($ red) for the 2005 hurricane season (June-November). Geographical domain for area-averaging covers the typical TC genesis region over the Atlantic that spans $5^{\circ}-20^{\circ} \mathrm{N}, 60^{\circ}-15^{\circ} \mathrm{W}$.

(not shown). Figure 11a shows that the latent heat flux is significantly increased in ExpA throughout the Atlantic basin. The enhanced evaporative flux from the ocean (Fig. 11b) gives rise to the increase in latent heat flux. We will see later (Fig. 12) that the upward flux at the surface is also enhanced by increased ascending motion in the unstable atmosphere. This is consistent with Zhao et al. (2012), who found that surface heat fluxes including latent heat flux were influenced by vertical motion, and that this was important for making the resolved-scale convection more favorable for tropical cyclone genesis.

Figures 11c quantifies the increase in conditional instability we inferred from Figs. 9-11b, in terms of CAPE. It shows that CAPE is significantly enhanced in ExpA (compared with the control) through the constraint on the parameterized deep convection. CAPE exists within the conditionally unstable layer of the troposphere, when a lifted parcel of air is warmer than the ambient air. It is to be expected, based on Fig. 10, that strong upper-tropospheric cooling overlying relatively warmer air at lower levels, accompanied by sufficient moisture, contributes to a build-up of CAPE. The larger CAPE in ExpA compared with the control run (ExpC) is also associated with an enhancement of the dynamically resolved convective processes leading to an increase in large-scale condensation and precipitation (see the fractional precipitation change in Fig. 15).

Figure 12a clearly illustrates the vertical motion (see also Oouchi et al. 2006) resulting from the restriction of parameterized deep convection. As expected, the suppression of parameterized deep convection leads to increased ascending motion over the TC genesis region throughout the vertical column with the largest increase occurring in ExpA, followed by ExpB and then ExpC. The enhanced vertical ascent is associated with enhanced low-level convergence (Fig. 13). This low-level convergence, combined with low-level moistening (Fig. 10) and positive latent heat flux (Fig. 11a), plays a role in increasing the moisture flux convergence at low levels (Fig. 12b), with the largest values occurring in ExpA, followed by ExpB and ExpC.

Figure 13 shows the distribution of the differences between ExpA and ExpC in some other atmospheric quantities. The results show that low-level vorticity $(850 \mathrm{hPa})$, near-surface wind variance $(10 \mathrm{~m})$, low-level convergence $(925 \mathrm{hPa})$, and vertically integrated moisture flux convergence are all enhanced over the eastern Atlantic. The enhancement is more pronounced over the $\mathrm{TC}$ genesis region between about $10^{\circ}$ and $15^{\circ} \mathrm{N}$ (for 

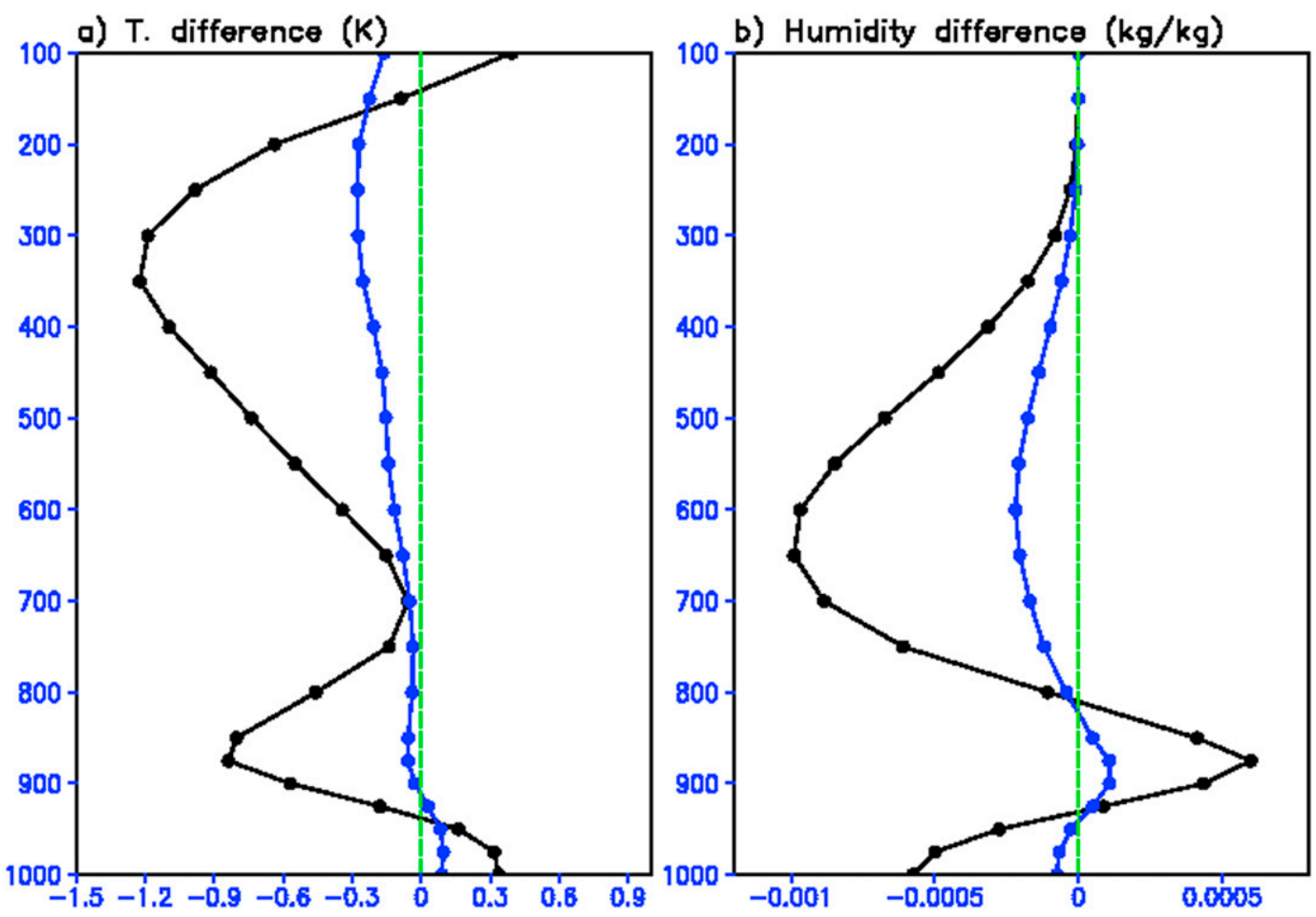

FIG. 10. (left) Vertical profile of area-averaged difference in (a) temperature (K) and (b) specific humidity $\left(\mathrm{kg} \mathrm{kg}^{-1}\right)$ for the 2005 hurricane season (June-November). Black curve denotes difference between ExpA and ExpC (ExpA minus ExpC) while the blue curve denotes difference between ExpB and ExpC (ExpB minus ExpC). Geographical domain for area-averaging covers the typical TC genesis region over the Atlantic that spans $5^{\circ}-20^{\circ} \mathrm{N}$, $60^{\circ}-15^{\circ} \mathrm{W}$.

genesis latitudes, see also Figs. 2 and 3). These spatial patterns emphasize once again that, as the parameterized deep convection is suppressed through an increase in the minimum entrainment threshold, the resulting increase in atmospheric instability makes dynamically resolved moist convection more active by enhancing low-level atmospheric motions (e.g., convergence, vorticity, and wind variance).

To quantify that the atmospheric structures discussed so far provide a favorable TC genesis environment, we next calculate the genesis potential index (GPI). Here, the original version of GPI (Emanuel and Nolan 2004) has been modified following Murakami et al. (2011) to include the influence of vertical motion in contributing to TC genesis. The modified $\mathrm{GPI}^{1}$ is given by

$$
\mathrm{GPI}=\left|10^{5} \eta\right|^{3 / 2}\left(\frac{\mathrm{RH}}{50}\right)^{3}\left(\frac{V_{\mathrm{pot}}}{70}\right)^{3}\left(1+0.1 V_{s}\right)^{-2}\left(\frac{-\omega+0.1}{0.1}\right)
$$

\footnotetext{
${ }^{1}$ The source code for the FORTRAN version of the maximum potential intensity [ $V_{\text {pot }}$ in Eq. (2)] calculation is available from ftp://texmex.mit.edu/pub/emanuel/TCMAX/pcmin_revised.f.
}

where $\eta$ is the absolute vorticity at $850-\mathrm{hPa}$ level, $\mathrm{RH}$ is the relative humidity in percent at $700 \mathrm{hPa}, V_{\text {pot }}$ is the maximum potential intensity (MPI; $\mathrm{m} \mathrm{s}^{-1}$ ) defined in Emanuel (1995), $V_{\mathrm{s}}$ is the vertical wind shear [V( $850 \mathrm{hPa})$ minus $V(200 \mathrm{hPa})]$, and $\omega$ is the vertical wind velocity $\left(\mathrm{Pas}^{-1}\right)$ at $500 \mathrm{hPa}$. Note that $V_{\text {pot }}$ is modified by Bister and Emanuel (1998) from the original version of Emanuel (1995) so that

$$
V_{\mathrm{pot}}^{2}=\frac{C_{k} T_{s}}{C_{d} T_{0}}\left(\mathrm{CAPE}^{*}-\mathrm{CAPE}^{b}\right),
$$

where $C_{k}$ and $C_{d}$ are the exchange coefficient for enthalpy and the drag coefficient, respectively. Also, $T_{s}$ is SST and $T_{0}$ is the mean outflow temperature. Two CAPE-related quantities, CAPE* and $\mathrm{CAPE}^{b}$, are the CAPE of the air displaced upward from saturation at sea level with reference to ambient air and the CAPE of the air at boundary layer, respectively.

The GPI formulation considers the influence of all the horizontal and vertical atmospheric structures and atmospheric instability discussed in reference to Figs. 913. As shown in Fig. 14, the GPI exhibits larger values in ExpA and ExpB than in the control run (ExpC). Large 


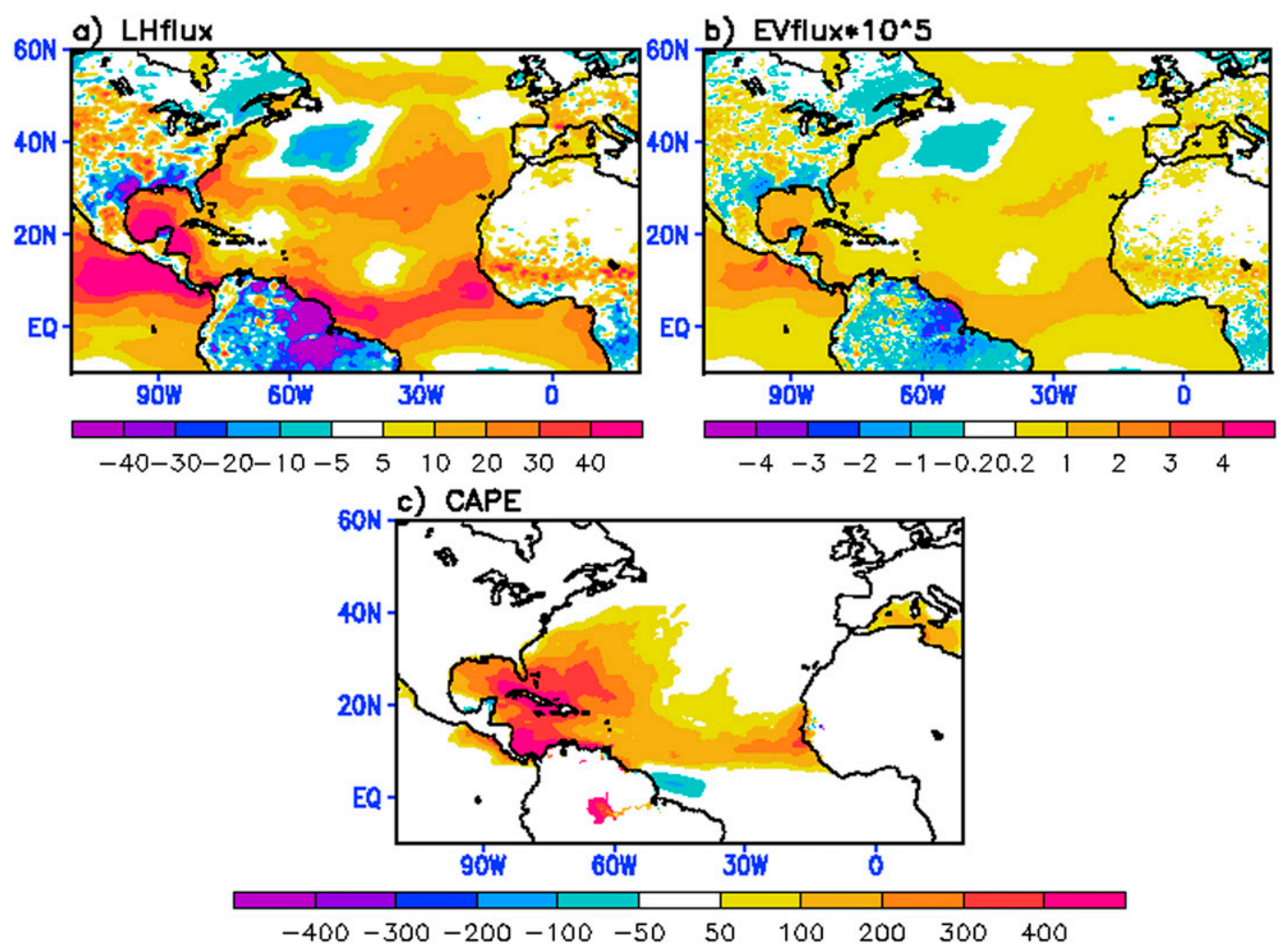

FIG. 11. Difference in (a) surface latent heat flux $\left(\mathrm{W} \mathrm{m}^{-2}\right)$, (b) evaporative flux $\left(\times 10^{-5} \mathrm{~W} \mathrm{~m}^{-2}\right)$, and (c) CAPE $\left(\mathrm{J} \mathrm{kg}^{-1}\right)$ between ExpA and ExpC (ExpA minus ExpC) during hurricane season (June-November) of 2005.

values occur over the Atlantic in low latitudes, the Caribbean Sea, and the Gulf of Mexico, where a majority of TC genesis takes place.

An important consideration is whether the above modifications in the convective parameterization produce changes in the atmospheric mean state and its variability (e.g., seasonal cycle) that are within acceptable ranges. Slingo et al. (1994) and Zhang and McFarlane (1995) found some sensitivity of the tropical mean climate to the parameterized moist convection. Figure 15 shows the differences between each experiment in the mean precipitation for 2005. We plot both the large-scale precipitation and convective precipitation to identify the fractional precipitation changes. The left panels show the difference between ExpA and ExpC in total precipitation (Fig. 15a), large-scale precipitation (Fig. 15b), and convective precipitation (Fig. 15c). The results show that both total and large-scale precipitation increase noticeably over the tropics for ExpA, whereas there is a substantial reduction in convective precipitation. In contrast, for $\mathrm{ExpB}$ (the right panels) there is only a very small change in total precipitation over the tropics (Fig. 15d), while the large-scale precipitation over the TC genesis region increases slightly (Fig. 15e) along with a decrease in convective precipitation (Fig. 15f).
This fractional precipitation change is known to be due to an increased activity of grid-scale cloud/ condensation (i.e., large-scale precipitation) along with a suppression of parameterized deep convection (i.e., convective precipitation) (Held et al. 2007; Reed and Jablonowski 2011; Zhao et al. 2012).

The area-averaged difference in total precipitation over the Atlantic basin between ExpB and ExpC (Table 3) is $0.03 \mathrm{~mm} \mathrm{day}^{-1}$ in 2005 and $0.09 \mathrm{~mm} \mathrm{day}^{-1}$ in 2006, while for ExpA the precipitation increases with respect to ExpC by 0.5 and $0.6 \mathrm{~mm} \mathrm{day}^{-1}$ in those two years, respectively. Globally $\left(50^{\circ} \mathrm{S}-50^{\circ} \mathrm{N}, 0^{\circ}-360^{\circ} \mathrm{E}\right)$, ExpA precipitation increases with respect to ExpC by $0.19 \mathrm{~mm} \mathrm{day}^{-1}$ in 2005 and $0.22 \mathrm{~mm} \mathrm{day}^{-1}$ in 2006 , while $\operatorname{ExpB}$ produces nearly the same precipitation rate as ExpC. However, all three experiments overestimate the observed precipitation (left column in Table 3; see also Fig. 16a) obtained from Tropical Rainfall Measuring Mission (TRMM) dataset (Huffman et al. 2007). Table 3 indicates that the excessive total precipitation in ExpA makes it a less than ideal model to use even though it has more intense hurricanes. Also, ExpA produces an excessive number of TCs during the inactive hurricane year of 2006 (Table 1). In contrast, ExpB seems a better option since 


\section{a) OMEGA*100}

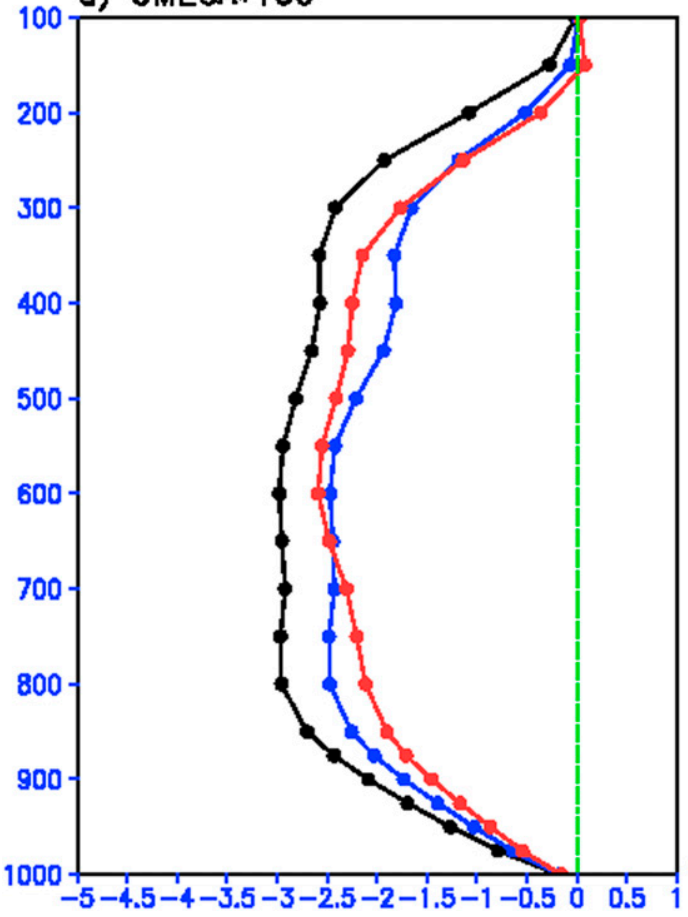

b) Moisture flux conv. $\$ 10^{\wedge} 8$

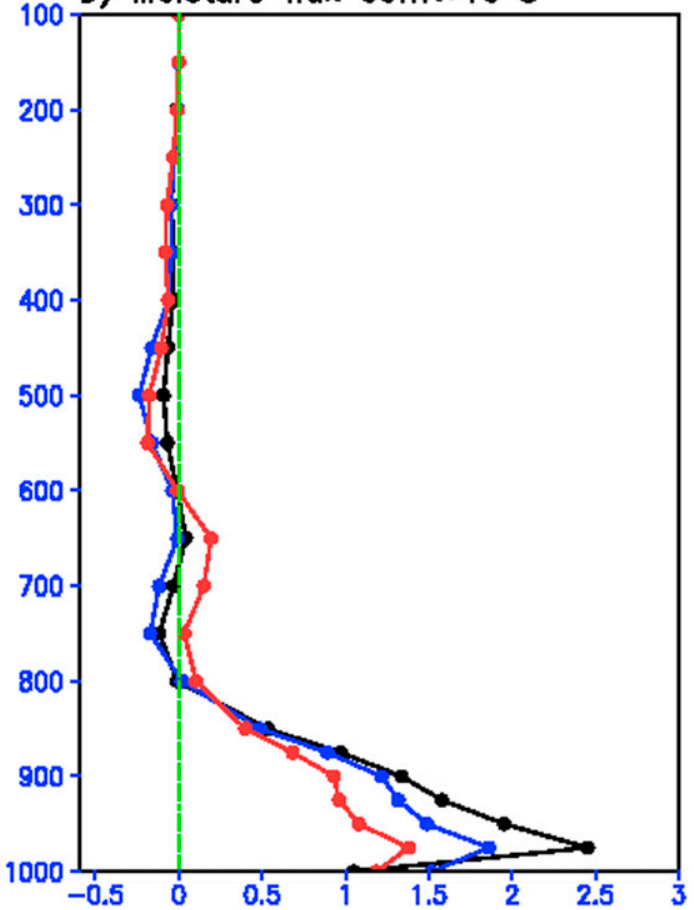

FIG. 12. The vertical profile of area-averaged (a) omega velocity $\left(\times 10^{-2} \mathrm{hPa} \mathrm{s}^{-1}\right)$ and (b) moisture flux convergence $\left(\times 10^{-8} \mathrm{~kg} \mathrm{~kg}^{-1} \mathrm{~s}^{-1}\right)$ for the hurricane season (June-November) of 2005. The geographical domain for areaaveraging covers the typical TC genesis region over the Atlantic that spans $5^{\circ}-20^{\circ} \mathrm{N}, 60^{\circ}-15^{\circ} \mathrm{W}$. Black, blue, and red curves denote results for ExpA, ExpB, and ExpC, respectively.

it has minimal impact on the total precipitation (amount and spatial distribution) produced by the control (ExpC) and has improved three-dimensional hurricane structures, intensities, and numbers, compared with the control (ExpC).

Figure 16 compares for each experiment the seasonal variation (June through November) of precipitation, SLP, surface temperature, upper-level wind speed, MPI as an instability value [see Eq. (3)], and GPI over the North Atlantic. We see that ExpB tends to remain close to ExpC in all the variables (precipitation, SLP, temperature, and wind speed) with a slight increase in MPI and GPI, whereas ExpA shows a noticeable increase in total precipitation, MPI, and GPI and a decrease in SLP compared to the control run. A comparison with observations (black dashed lines) indicates that, except for the upper-level wind speed, ExpA tends to have larger biases than either ExpB or the control (ExpC). Overall, our results suggests that a small reduction in the influence of the RAS convective parameterization (ExpB) produces improved North Atlantic TC activity without having a negative impact on the mean climate of the model when run at $0.25^{\circ}$ horizontal grid spacing.

\section{Concluding remarks and discussion}

This study investigated the sensitivity of the North Atlantic TC activity to changes in parameterized deep convection in the NASA GEOS-5 model run at $0.25^{\circ}$ latitude/longitude horizontal grid spacing. The study found that reduction in the influence of the RAS scheme resulting from an increase in minimum entrainment for parameterized deep convection improves/enhances (compared to the standard control model) the TC activity in terms of numbers, intensity, life cycle, and the threedimensional storm structures. Our case studies for the 2005 (very active) and 2006 (very inactive) hurricane seasons revealed that only a modest increase in minimum entrainment (ExpB) was necessary at a quarterdegree grid spacing to produce TC numbers reasonably close to observations. The strongest hurricane reached a minimum SLP of $940 \mathrm{hPa}$ and low-level maximum wind speeds greater than $60 \mathrm{~m} \mathrm{~s}^{-1}$. The vertical structure is characterized by a well-defined hurricane eye, an upper-tropospheric warm core value exceeding $10^{\circ} \mathrm{C}$, and maximum winds located at low levels within $50 \mathrm{~km}$ of the hurricane center. These magnitudes are comparable to, or an improvement over, those of Shen 

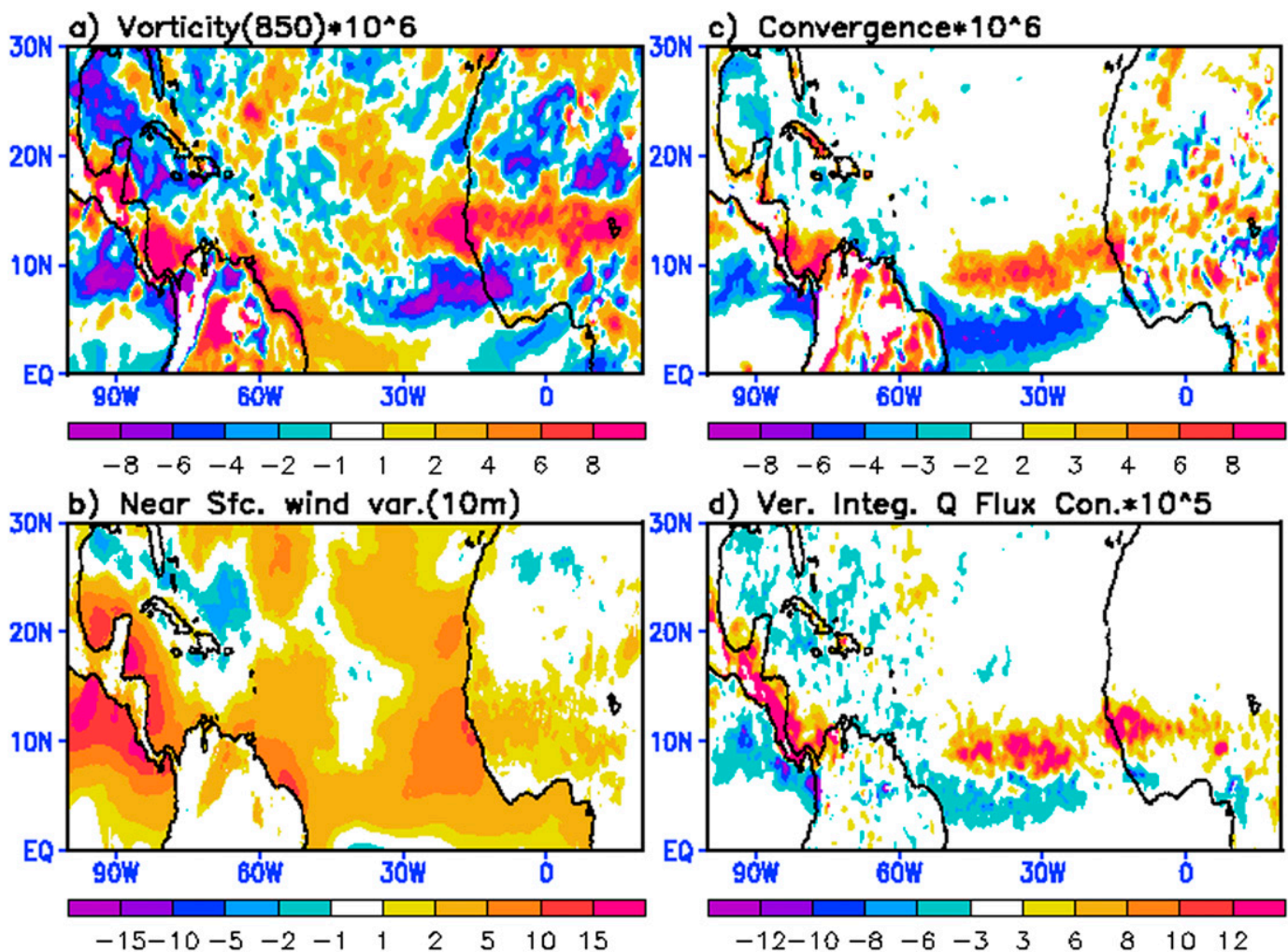

FIG. 13. Difference in (a) relative vorticity $\left(\times 10^{-6} \mathrm{~s}^{-1}\right)$ at $850 \mathrm{hPa},(\mathrm{b})$ wind variance $\left(\mathrm{m}^{2} \mathrm{~s}^{-2}\right)$ at $10-\mathrm{m}$ level, (c) convergence $\left(\times 10^{-6} \mathrm{~s}^{-1}\right)$ at $925 \mathrm{hPa}$, and (d) vertically integrated moisture flux convergence $\left(\times 10^{-5} \mathrm{~kg} \mathrm{~m}^{-2} \mathrm{~s}^{-1}\right)$ between ExpA and ExpC (ExpA minus ExpC) during hurricane season (June-November) of 2005.

et al. (2006) and Reed and Jablonowski (2011) at similar resolution. Furthermore, we found that a stronger constraint on the parameterized deep convection (i.e., ExpA) produced even stronger hurricanes (with minimum SLP of $935 \mathrm{hPa}$, and a maximum wind speed of $65 \mathrm{~m} \mathrm{~s}^{-1}$ ), but this strong reduction in parameterized convection was not desirable as it produced strong TC activity even in a weak hurricane year (2006) and led to increased bias in the atmospheric mean state.

Our analysis of the causes of the TC changes suggests that the following processes are at work. First, an increase in the threshold of minimum entrainment causes more entrainment of dry air into the convective plume. This entraining process leads to a reduction in buoyancy, resulting in less favorable conditions for deep convection. Reduced deep convection leads to a reduction in condensation heating in the upper troposphere, resulting in upper-tropospheric cooling. As a result, the mid to upper troposphere becomes drier and cooler, while the lower troposphere becomes moister. This moistening appears associated with the upward flux of the positive latent heat flux (evaporative flux) from the ocean to the lower atmosphere. This change in the vertical structure of the atmosphere is apparent over the Atlantic basin, easing the condition for enhancing atmospheric instability. The greater instability is evidenced by changes in the profile of moist static energy, the vertical gradient of equivalent potential temperature, and the distribution of CAPE. As a consequence to the changes in atmospheric instability there is an increase in 1) low-level positive vorticity and convergence, 2) upward motion, and 3) low-level moisture flux convergence. These changes help the development of explicit-scale convection and subsequent large-scale condensation of water vapor, and represent a transition of the moist deep convection from the parameterized kind to that occurring at the resolved scales. This is reflected by a decrease in convective precipitation contributed by parameterized convection and an increase in large-scale precipitation. The above interpretation is supported by the changes in the GPI (Emanuel and Nolan 2004; Murakami et al. 2011) showing an enhancement in the TC activity over the Atlantic, with more and stronger TCs than the control run (e.g., strong hurricanes with wind speed and SLP close to $60 \mathrm{~m} \mathrm{~s}^{-1}$ and $940 \mathrm{hPa}$, respectively, were produced, whereas the control never produced such a strong hurricane).

While our focus has been on atmospheric instability and associated circulatory structure to explain change in TC activity, there is evidence to suggest that parameterized 


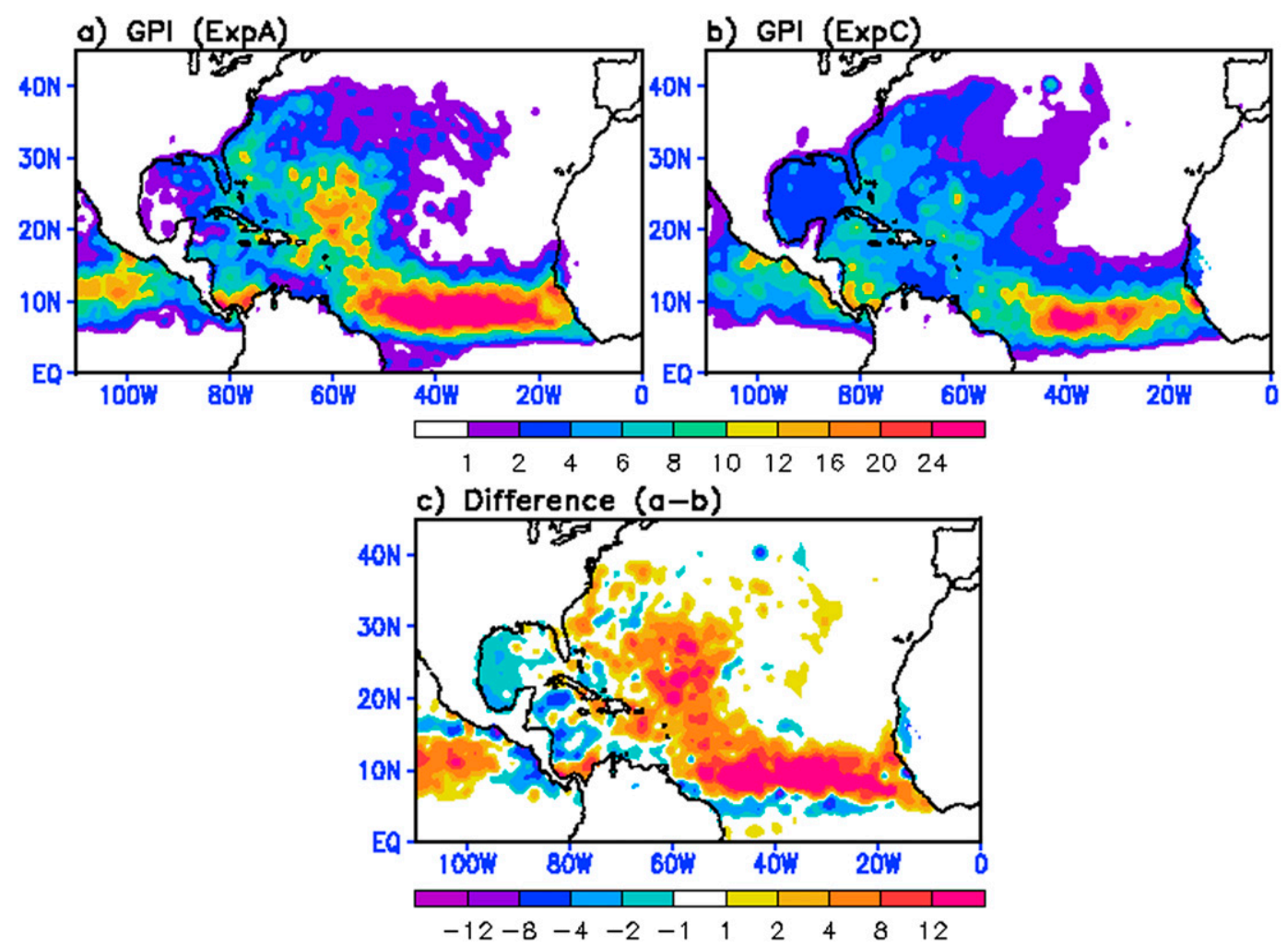

FIG. 14. Distribution of modified genesis potential indices for 2005 from (a) ExpA and (b) ExpC, and (c) their difference (ExpA minus ExpC).

convective momentum adjustment (CMA) may also be important (e.g., Han and Pan 2006). The effect of CMA in the RAS scheme (Moorthi et al. 2001) tends to decrease as the activity of RAS scheme reduces, resulting in diminution of the role of CMA as a TC-inhibiting factor. We checked zonal wind tendency due to moist process (ZWTM), as an example to have some sense as to how substantially the CMA can change with the RAS scheme reduction. Global average of tropospheric ZWTMs in ExpA was a little less than a half of the global mean ZWTM in control run, whereas the ExpB showed about $90 \%$ of the ZWTM in control run. It indicates that the reduced CMA in ExpA could be influential to change TC activity, while the CMA in ExpB may play much less role in changing TC activity seen in control run. More critical exploration of the role of CMA will be performed in further detail in the next study.

The explicit-scale moist convection favored by atmospheric instability appears to compensate for the uppertropospheric cooling and drying produced by the reduction in parameterized deep convection, with the atmosphere acting to maintain thermal equilibrium in the upper troposphere. This likely explains why, at least for the experiment with only a modest change in the threshold of minimum entrainment (ExpB), the total precipitation remains close to that of the control.
Because of the limited number of cases investigated here, it is premature to say that ExpB truly represents an optimal setting for the reliable simulation of TCs at this grid spacing. Nevertheless, the current set of experiments are encouraging in that they demonstrate how years with widely differing TC activity (2005 and 2006) can be reproduced by global climate model with a rather minor change to the convective parameterization, and that this can be done without degrading the mean state.

This article suggests that a quarter-degree may be the minimum horizontal grid spacing necessary for achieving realistic TC simulations via modifications to the parameterized convective process (Reed and Jablonowski 2011), while still maintaining a realistic mean state. This conclusion is based in part on other experiments we carried out at one-half and one-third degree grid spacing (not shown), in which realistic TC numbers were difficult to achieve without modifying the threshold values for TC detection. Of course the results at $0.25^{\circ}$ grid spacing still have several limitations. Key among them is the inability to produce the most intense (category 5 ) hurricanes. It appears that even at substantially finer than a quarterdegree grid spacing, finescale hurricane structure can be improved through the modification of the convective parameterization. For example, Putman and Suarez 

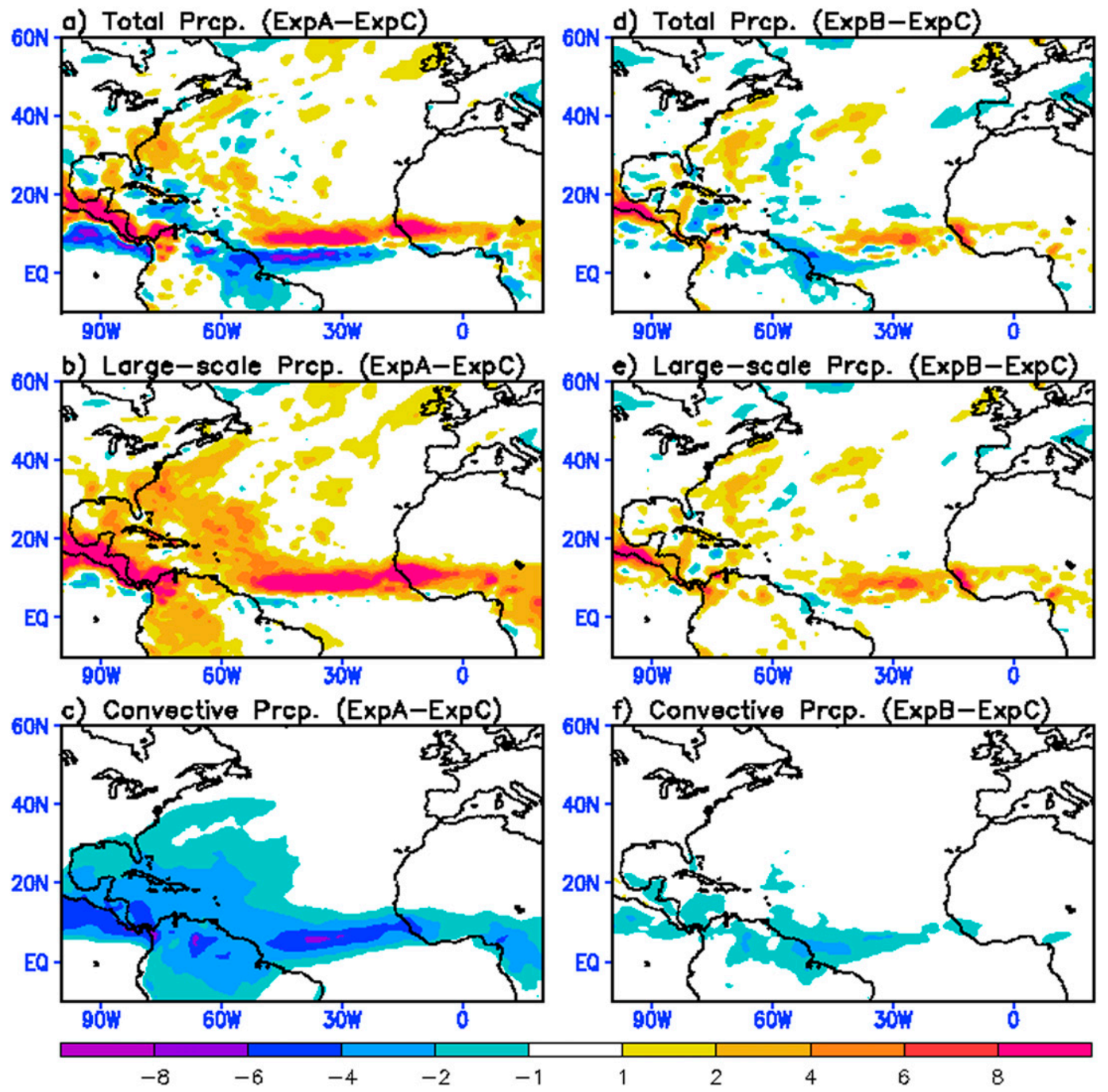

FIG. 15. (left) Difference in (a) total precipitation, (b) large-scale precipitation, and (c) convective precipitation between ExpA and ExpC (ExpA minus ExpC) during 2005 hurricane season. (right) As at (left), but for the difference between $\operatorname{ExpB}$ and $\operatorname{ExpC}\left(\operatorname{ExpB}\right.$ minus ExpC). Unit of precipitation is $\mathrm{mm}$ day $^{-1}$.

(2011) concluded from the analysis of GEOS-5 forecasts run at $7-\mathrm{km}$ horizontal grid spacing that intense precipitation was better formed within the hurricane eyewall and surrounding rain bands with a reduction in the influence of the RAS convective parameterization, compared to a control in which RAS was not modified. As such it appears that, even at considerably higher grid spacing than considered here, improvements in the

TABLE 3. Difference in total precipitation averaged over the North Atlantic basin (the second and the third row), which covers $0^{\circ} \mathrm{N}-$ $50^{\circ} \mathrm{N}, 90^{\circ} \mathrm{W}-0^{\circ} \mathrm{E}$, and globally $\left(50^{\circ} \mathrm{S}-50^{\circ} \mathrm{N}, 0^{\circ}-360^{\circ} \mathrm{E}\right.$; the fourth and the fifth row). Difference between ExpA and control run is shown in the middle column whereas the difference between ExpB and control run in the right column. The second and the fourth row represent the results for the year 2005 whereas the third and the fifth row are for the year 2006. Observed precipitation on the left column is obtained from the Tropical Rainfall Measuring Mission (TRMM) dataset, which is $0.25^{\circ}$ lon/lat gridded.

\begin{tabular}{llll}
\hline \hline & & ExpA minus ExpC & ExpB minus ExpC \\
\hline Total precipitation over North Atlantic & 2005 (Obs. $=4.02)$ & $4.89-4.40=0.49$ & $4.43-4.40=0.03$ \\
& $2006($ Obs. $=3.88)$ & $5.02-4.42=0.60$ & $4.51-4.42=0.09$ \\
Global $\left(50^{\circ} \mathrm{S}-50^{\circ} \mathrm{N}, 0^{\circ}-360^{\circ} \mathrm{E}\right)$ total & 2005 (Obs. $=2.92)$ & $3.54-3.35=0.19$ & $3.36-3.35=0.01$ \\
precipitation & 2006 (Obs. $=2.93)$ & $3.56-3.34=0.22$ & $3.37-3.34=0.03$ \\
\hline
\end{tabular}


a) Total Prcp.

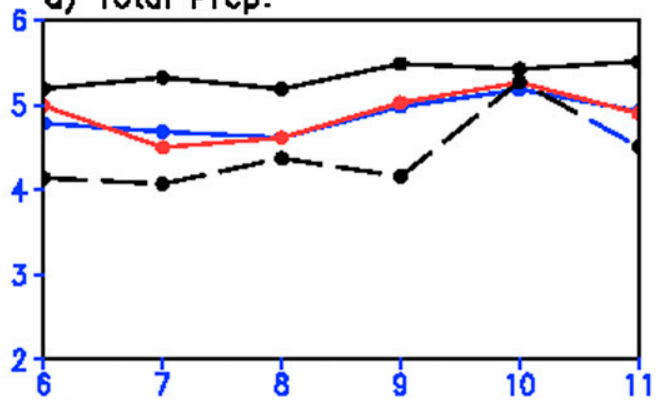

b) SLP
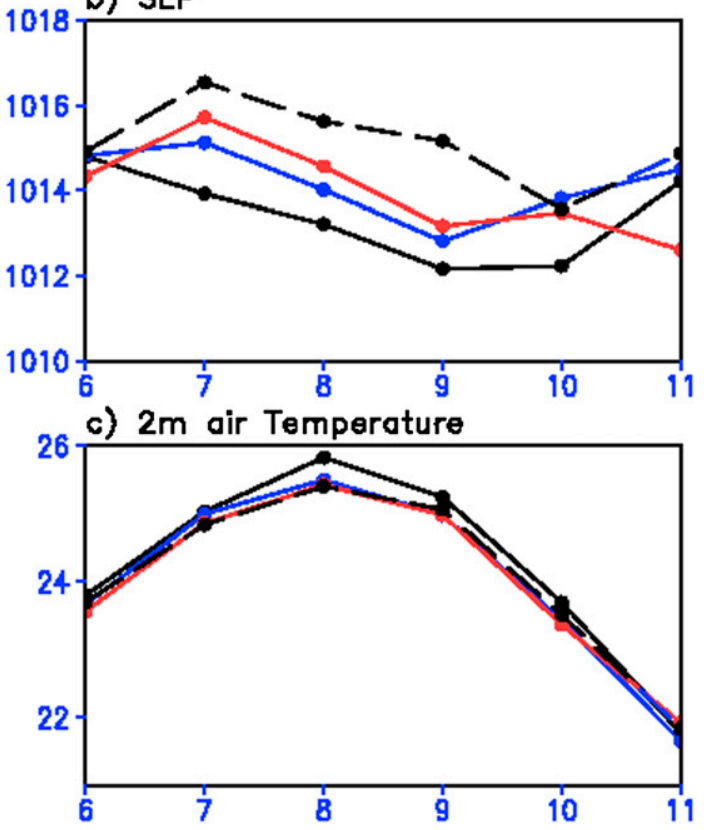

d) UV200 speed

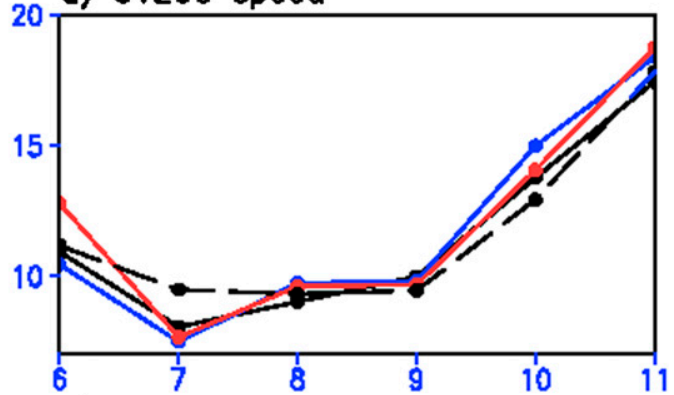

e) Maximum Potential Intensity
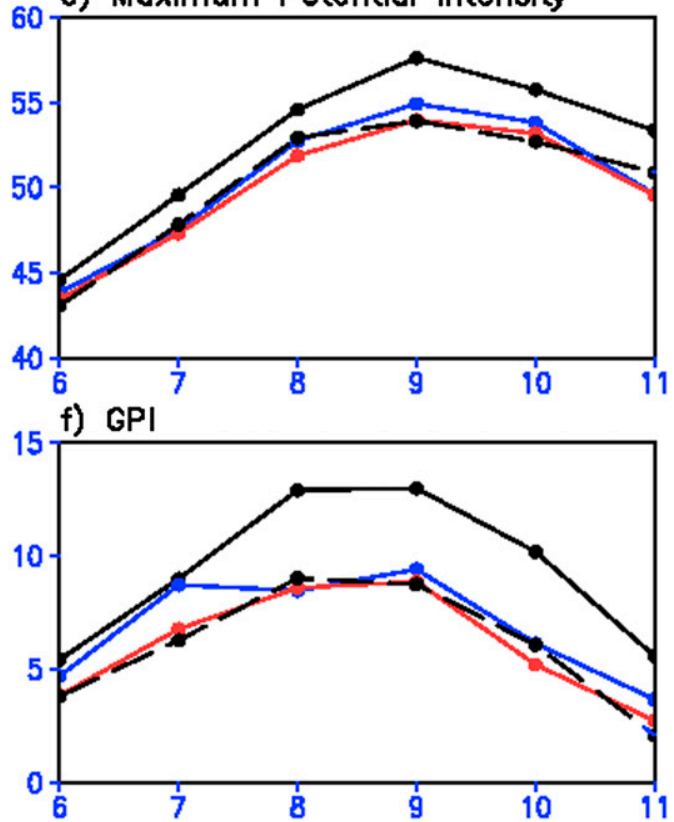

FIG. 16. The seasonal variation of the area-averaged (a) total precipitation (mm day ${ }^{-1}$ ), (b) SLP (hPa), (c) 2-m air temperature $\left({ }^{\circ} \mathrm{C}\right),(\mathrm{d}) 200-\mathrm{hPa}$ wind speed $\left(\mathrm{m} \mathrm{s}^{-1}\right)$, (e) MPI $\left(\mathrm{m} \mathrm{s}^{-1}\right)$, and (f) GPI for 2005. The geographical domain for area-averaging covers the North Atlantic that spans $0^{\circ}-50^{\circ} \mathrm{N}, 90^{\circ}-15^{\circ} \mathrm{W}$. Black, blue, and red solid lines represent the results from ExpA, ExpB, and ExpC, respectively. The observed (TRMM) precipitation and remaining variables and quantities (MPI and GPI) derived from MERRA are plotted with black dashed lines.

simulation of TC activity can still benefit from a proper modification of the convective parameterization.

Acknowledgments. This work is supported by the NASA Modeling, Analysis, and Prediction (MAP) Program. The authors are grateful to anonymous reviewers for their helpful comments and suggestions.

\section{REFERENCES}

Arakawa, A., and W. H. Schubert, 1974: Interaction of cumulus cloud ensemble with the large-scale environment. Part I. J. Atmos. Sci., 31, 671-701, doi:10.1175/1520-0469(1974)031<0674: IOACCE $>2.0 . \mathrm{CO} ; 2$.

Atlas, R., and Coauthors, 2005: Hurricane forecasting with the highresolution NASA finite volume general circulation model. Geophys. Res. Lett., 32, L03807, doi:10.1029/2004GL021513.
Bacmeister, J. T., and G. L. Stephens, 2011: Spatial statistics of likely convective clouds in CloudSat data. J. Geophys. Res., 116, D04104, doi:10.1029/2010JD014444.

—, M. F. Wehner, R. B. Neale, A. Gettelman, C. Hannay, P. H. Lauritzen, J. M. Caron, and J. E. Truesdale, 2014: Exploratory high-resolution climate simulations using the Community Atmosphere Model (CAM). J. Climate, 27, 3073-3099, doi:10.1175/JCLI-D-13-00387.1.

Bister, M., and K. A. Emanuel, 1998: Dissipative heating and hurricane activity. Meteor. Atmos. Phys., 65, 233-240, doi:10.1007/BF01030791.

Caron, L.-P., C. G. Jones, and K. Winger, 2011: Impact of resolution and downscaling technique in simulating recent Atlantic tropical cyclone activity. Climate Dyn., 37, 869-892, doi:10.1007/s00382-010-0846-7.

Daloz, A.-S., F. Chauvin, K. Walsh, S. Lavender, D. Abbs, and F. Roux, 2012: The ability of GCMs to simulate tropical cyclones and their precursors over the North Atlantic main development region. Climate Dyn., 39, 1559-1576, doi:10.1007/s00382-012-1290-7. 
Emanuel, K. A., 1995: Sensitivity of tropical cyclones to surface exchange coefficients and a revised steady-state model incorporating eye dynamics. J. Atmos. Sci., 52, 3969-3976, doi:10.1175/ 1520-0469(1995)052<3969:SOTCTS $>2.0$.CO;2.

- 2013: Downscaling CMIP5 climate models shows increased tropical cyclone activity over the 21st century. Proc. Natl. Acad. Sci. USA, 110, 12219-12 224, doi:10.1073/pnas.1301293110.

, and D. S. Nolan, 2004: Tropical cyclone activity and global climate. 26th Conf. on Hurricanes and Tropical Meteorology, Miami, FL, Amer. Meteor. Sci., 240-241.

, R. Sundararajan, and J. Williams, 2008: Hurricanes and global warming: Results from downscaling IPCC AR4 simulations. Bull. Amer. Meteor. Soc., 89, 347-367, doi:10.1175/ BAMS-89-3-347.

Frank, W. M., 1977: The structure and energetics of the tropical cyclone. I. Storm structure. Mon. Wea. Rev., 105, 1119-1135, doi:10.1175/1520-0493(1977)105<1119:TSAEOT>2.0.CO;2.

Gent, P. R., and Coauthors, 2011: The Community Climate System Model version 4. J. Climate, 24, 4973-4991, doi:10.1175/ 2011JCLI4083.1.

Han, J., and H.-L. Pan, 2006: Sensitivity of hurricane intensity forecast to convective momentum transport parameterization. Mon. Wea. Rev., 134, 664-674, doi:10.1175/MWR3090.1.

Held, I. M., M. Zhao, and B. Wyman, 2007: Dynamic radiativeconvective equilibria using GCM column physics. J. Atmos. Sci., 64, 228-238, doi:10.1175/JAS3825.11.

Huffman, G. J., and Coauthors, 2007: The TRMM Multisatellite Precipitation Analysis (TMPA): Quasi-global, multi-year, combined-sensor precipitation estimates at fine scales. $J$. $H y$ drometeor., 8, 38-55, doi:10.1175/JHM560.1.

Kang, S. M., I. M. Held, D. M. W. Frierson, and M. Zhao, 2008: The response of the ITCZ to extratropical thermal forcing: Idealized slab-ocean experiments with a GCM. J. Climate, 21, 35213532, doi:10.1175/2007JCLI2146.1.

Knapp, K. R., M. C. Kruk, D. H. Levinson, H. J. Diamond, and C. J. Neumann, 2010: The International Best Track Archive for Climate Stewardship (IBTrACS): Unifying tropical cyclone data. Bull. Amer. Meteor. Soc., 91, 363-376, doi:10.1175/ 2009BAMS2755.1.

Knutson, T. R., and R. E. Tuleya, 2004: Impact of $\mathrm{CO}_{2}$-induced warming on simulated hurricane intensity and precipitation: Sensitivity to the choice of climate model and convective parameterization. J. Climate, 17, 3477-3495, doi:10.1175/ 1520-0442(2004)017<3477:IOCWOS>2.0.CO;2.

- J. J. Sirutis, S. T. Garner, I. M. Held, and R. E. Tuleya, 2007: Simulation of the recent multidecadal increase of Atlantic hurricane activity using an $18-\mathrm{km}$-grid regional model. Bull. Amer. Meteor. Soc., 88, 1549-1565, doi:10.1175/BAMS-88-10-1549.

LaRow, T., Y.-K. Lim, D. Shin, E. Chassignet, and S. Cocke, 2008: Atlantic basin seasonal hurricane simulations. J. Climate, 21, 3191-3206, doi:10.1175/2007JCLI2036.1.

Lee, M.-I., I.-S. Kang, and B. E. Mapes, 2003: Impacts of cumulus convection parameterization on aqua-planet AGCM simulations of tropical intraseasonal variability. J. Meteor. Soc. Japan, 81, 963-992, doi:10.2151/jmsj.81.963.

Lin, J.-L., M.-I. Lee, D. Kim, I.-S. Kang, and D. M. W. Frierson, 2008: Impacts of convective parameterization and moisture convective trigger on AGCM-simulated convectively coupled equatorial waves. J. Climate, 21, 883-909, doi:10.1175/2007JCLI1790.1.

Ma, L.-M., and Z.-M. Tan, 2009: Improving the behavior of the cumulus parameterization for tropical cyclone prediction: Convection trigger. Atmos. Res., 92, 190-211, doi:10.1016/ j.atmosres.2008.09.022.
Mallard, M. S., G. M. Lackmann, A. Aiyyer, and K. A. Hill, 2013: Atlantic hurricanes and climate change. Part I: Experimental design and isolation of thermodynamic effects. J. Climate, 26, 4876-4893, doi:10.1175/JCLI-D-12-00182.1.

Manabe, S., 1969: Climate and the ocean circulation: I. The atmospheric circulation and the hydrology of the Earth's surface. Mon. Wea. Rev., 97, 739-774, doi:10.1175/1520-0493(1969)097<0739: CATOC $>2.3 . \mathrm{CO} ; 2$.

Molod, A., L. Takacs, M. Suarez, J. Bacmeister, I.-S. Song, and A. Eichmann, 2012: The GEOS-5 atmospheric general circulation model: Mean climate and development from MERRA to Fortuna. NASA Tech. Rep. NASA TM-2012-104606, Vol. 28, $117 \mathrm{pp}$.

Moorthi, S., and M. J. Suarez, 1992: Relaxed Arakawa-Schubert: A parameterization of moist convection for general circulation models. Mon. Wea. Rev., 120, 978-1002, doi:10.1175/ 1520-0493(1992)120<0978:RASAPO > 2.0.CO;2.

_ , H.-L. Pan, and P. Caplan, 2001: Changes to the 2001 NCEP operational MRF/AVN global analysis/forecast system. NWS Tech. Bull. 484, 14 pp.

Murakami, H., B. Wang, and A. Kitoh, 2011: Future change of western North Pacific typhoons: Projections by a 20-km-mesh global atmospheric model. J. Climate, 24, 1154-1169, doi:10.1175/2010JCLI3723.1.

— , and Coauthors, 2012: Future changes in tropical cyclone activity projected by the new high-resolution MRI-AGCM. J. Climate, 25, 3237-3260, doi:10.1175/JCLI-D-11-00415.1.

Noda, A. T., K. Oouchi, M. Satoh, and H. Tomita, 2012: Quantitative assessment of diurnal variation of tropical convection simulated by a global nonhydrostatic model without cumulus parameterization. J. Climate, 25, 5119-5134, doi:10.1175/ JCLI-D-11-00295.1.

Oouchi, K., J. Yoshimura, H. Yoshimura, R. Mizuta, S. Kusunoki, and A. Noda, 2006: Tropical cyclone climatology in a globalwarming climate as simulated in a $20-\mathrm{km}$ mesh global atmospheric model: Frequency and wind intensity analysis. J. Meteor. Soc. Japan, 84, 259-276, doi:10.2151/jmsj.84.259.

Putman, W. M., and M. Suarez, 2011: Cloud-system resolving simulations with the NASA Goddard Earth Observing System global atmospheric model (GEOS-5). Geophys. Res. Lett., 38, L16809, doi:10.1029/2011GL048438.

Rayner, N. A., and Coauthors, 2003: Global analyses of sea surface temperature, sea ice, and night time air temperature since the late nineteenth century. J. Geophys. Res., 108, 4407, doi:10.1029/ 2002JD002670.

Reed, K. A., and C. Jablonowski, 2011: Impact of physical parameterizations on idealized tropical cyclones in the Community Atmosphere Model. Geophys. Res. Lett., 38, L04805, doi:10.1029/2010GL046297.

Rienecker, M. M., and Coauthors, 2008: The GEOS-5 data assimilation system - documentation of versions 5.0.1 and 5.1.0, and 5.2.0. NASA Tech. Rep. NASA/TM-2008-104606, Vol. 27, 92 pp. , and Coauthors, 2011: MERRA-NASA's Modern-Era Retrospective Analysis for Research and Applications. J. Climate, 24, 3624-3648, doi:10.1175/JCLI-D-11-00015.1.

Sanderson, B. M., C. Piani, W. Ingram, D. Stone, and M. Allen, 2008: Towards constraining climate sensitivity by linear analysis of feedback patterns in thousands of perturbed-physics GCM simulations. Climate Dyn., 30, 175-190, doi:10.1007/ s00382-007-0280-7.

Shaevitz, D. A., and Coauthors, 2014: Characteristics of tropical cyclones in high-resolution models in the present climate. $J . A d v$. Model. Earth Syst., doi:10.1002/2014MS000372, in press. 
Shen, B.-W., R. Atlas, O. Reale, S.-J. Lin, J.-D. Chen, J. Chang, C. Henze, and J.-L. Li, 2006: Hurricane forecasts with a global mesoscale-resolving model: Preliminary results with Hurricane Katrina (2005). Geophys. Res. Lett., 33, L13813, doi:10.1029/ 2006GL026143.

Shen, W., R. E. Tuleya, and I. Ginnis, 2000: A sensitivity study of the thermodynamic environment on GFDL model hurricane intensity: Implications for global warming. J. Climate, 13, 109-121, doi:10.1175/1520-0442(2000)013<0109:ASSOTT>2.0.CO;2.

Simpson, J., and V. Wiggert, 1969: Models of precipitating cumulus towers. Mon. Wea. Rev., 97, 471-480, doi:10.1175/ 1520-0493(1969)097<0471:MOPCT>2.3.CO;2.

Slingo, J., and Coauthors, 1994: Mean climate and transience in the tropics of the UGAMP GCM: Sensitivity to convective parameterization. Quart. J. Roy. Meteor. Soc., 120, 881-922, doi:10.1002/qj.49712051807.

Smith, R. K., 2000: The role of cumulus convection in hurricanes and its representation in hurricane models. Rev. Geophys., 38, 465-489, doi:10.1029/1999RG000080.

Stan, C., 2012: Is cumulus convection the concertmaster of tropical cyclone activity in the Atlantic? Geophys. Res. Lett., 39, L19716, doi:10.1029/2012GL053449.

Stephens, G., and Coauthors, 2002: The CloudSat mission and the A-Train. Bull. Amer. Meteor. Soc., 83, 1771-1790, doi:10.1175/ BAMS-83-12-1771.

Strachan, J., P.-L. Vidale, K. Hodges, M. Roberts, and M.-E. Demory, 2013: Investigating global tropical cyclone activity with a hierarchy of AGCMs: The role of model resolution. J. Climate, 26, 133152, doi:10.1175/JCLI-D-12-00012.1.

Tiedtke, M., 1993: Representation of clouds in large-scale models. Mon. Wea. Rev., 121, 3040-3061, doi:10.1175/1520-0493(1993)121<3040: ROCILS $>2.0 . \mathrm{CO} ; 2$.
Tokioka, T., K. Yamazaki, A. Kitoh, and T. Ose, 1988: The equatorial 30-60 day oscillation and the Arakawa-Schubert penetrative cumulus parameterization. J. Meteor. Soc. Japan, 66, 883-901.

Vitart, F., J. L. Anderson, J. Sirutis, and R. E. Tuleya, 2001: Sensitivity of tropical storms simulated by a general circulation model to changes in cumulus parameterization. Quart. J. Roy. Meteor. Soc., 127, 25-51, doi:10.1002/qj.49712757103.

- D. D. Anderson, and T. Stockdale, 2003: Seasonal forecasting of tropical cyclone landfall over Mozambique. J. Climate, 16, 39323945, doi:10.1175/1520-0442(2003)016<3932:SFOTCL >2.0.CO;2.

Walsh, K. J. E., M. Fiorino, C. W. Landsea, and K. L. McInnes, 2007: Objectively determined resolution-dependent threshold criteria for the detection of tropical cyclones in climate models and reanalyses. J. Climate, 20, 2307-2314, doi:10.1175/JCLI4074.1.

$\longrightarrow$, S. Lavender, E. Scoccimarro, and H. Murakami, 2013: Resolution dependence of tropical cyclone formation in CMIP3 and finer resolution models. Climate Dyn., 40, 585-599, doi:10.1007/s00382-012-1298-z.

Wang, Z., 2014: Role of cumulus congestus in tropical cyclone formation in a high-resolution numerical model simulation. J. Atmos. Sci., 71, 1681-1700, doi:10.1175/JAS-D-13-0257.1.

Zhang, G. J., and N. A. McFarlane, 1995: Sensitivity of climate simulations to the parameterization of cumulus convection in the Canadian Climate Centre general circulation model. Atmos.-Ocean, 33, 407-446, doi:10.1080/07055900.1995.9649539.

Zhao, M., I. M. Held, S.-J. Lin, and G. A. Vecchi, 2009: Simulations of global hurricane climatology, interannual variability, and response to global warming using a $50-\mathrm{km}$ resolution GCM. J. Climate, 22, 6653-6678, doi:10.1175/2009JCLI3049.1. , and - 2012: Some counterintuitive dependencies of tropical cyclone frequency on parameters in a GCM. J. Atmos. Sci., 69, 2272-2283, doi:10.1175/JAS-D-11-0238.1. 